УДК 331.56$]: 338.23: 336.74\}: 330.42$

$338.5]: 338.23: 336.74\}: 330.42$

$331.2]: 338.23: 336.74\}: 330.42$

\title{
MONETARY POLICY EFFECTIVENESS, AND SOME EXPLANATIONS OF UNEMPLOYMENT, FAIR WAGES AND FAIR PRICES IN A GENERAL EQUILIBRIUM SETTING
}

\author{
Dushko Josheski ${ }^{1}$; Tatjana Boshkov ${ }^{2}$
}

\begin{abstract}
This paper argues that monetary policy matters in short-run and that it affects unemployment, and prices and wages in near-rational firms. Those profit-maximizer firms are adjusting prices in accordance with consumer expectations and wages are set to be fair accordingly to the workers expectations. This is in exercise is all happening in New Keynesian dynamic stochastic general equilibrium setting which shall be compared to a Real business cycle model with technology shocks.
\end{abstract}

Key words: DSGE models, fair wages, fair prices, New Keynesian economics JEL:

\section{Introduction}

John Maynard Keynes in his The General Theory of Employment, Interest and Money (1936), in Book I:Chapter 3 Principles of the effective demand asserted that:" ... volume of employment in equilibrium depends on (i) the aggregate supply function, , (ii) the propensity to consume, and (iii) the volume of investment... This is the essence of the General Theory of Employment". In this system aggregate supply function is the sum of "the amount which the community is expected to spend on consumption" and "the amount which it is expected to devote to new investment" or ".."is what we have called above the effective demand". Then Keynes argued that capitalist economy could poses equilibria that are characterized by the persistent involuntary unemployment, see also, Akerlof,Yellen (1987).Keynes analyzed that the key departure from the self-interested maximizing behavior is the assumed stickiness of money wages. Workers typically resists money wage reduction but.."..not to resist real money wage reductions". Next, monetary policy can have large and long-lasting effect on interest rates and activity. A large literature based on Taylor (1979)-Calvo (1983) foundations, asserted that money growth (change) has a maximum effect on activity after one year, and that effect is gone in 3 years. Taylor-Calvo equations are capturing staggering and price decisions and are the basis modeling nominal rigidity in New Keynesian DSGE models. Monetary policy affects actual and natural rate of unemployment. Diamond (1982) model implied that there may be continuum of natural rates which may not be efficient, and it is in fact coordination failure. Hysteresis also is one channel through which monetary policy by inducing for sufficiently long period high interest rates can lead to increase in natural rate, see Blanchard, Summers (1986). The notion of unemployment whether is mismatch the central bank actions could be misguide and if it is a business cycle related FED "...could act to reduce it without touching of inflation", wrote

\footnotetext{
${ }^{1}$ Dushko Josheski, Assistant professor Goce Delcev University of Shtip, Faculty of tourism and business logistics, R.North Macedonia, dusko.josevski@ugd.edu.mk

2 Tatjana Boshkov, Associate professor, Goce Delcev University of Shtip, Faculty of tourism and business logistics, R.North Macedonia, tatjana.dzaleva@ugd.edu.mk
} 
Diamond (2011) in his column. Now in the case of matching, early search theory assumed the existence of a distribution of wage offers for identical jobs; unemployment arose in equilibrium because workers rejected low-wage jobs. This aspect of the theory was criticized both on logical grounds by Rothschild (1973) and on empirical grounds by Tobin (1972) ${ }^{1}$; Barron (1975) ${ }^{2}$. Rothschild (1973), asserted that the models of Mortensen (1970a,1970b) and Phelps (1970), while they do attempt to explain the behavior of the both sides of the labor market, they do not explain variety of wage offers which motivate the job seekers. One equilibrium model that met Rothschild's criticisms, was first presented by Lucas and Prescott (1974). Early applications of the concept of the matching function that downplay the role of reservation wages include Hall (1979), Pissarides (1979), and Bowden (1980). Diamond and Maskin (1979) used the similar concept of "search technology" in a related context. The application of zero-profit conditions for new jobs, leading to a closed model with endogenous demand for labor, was first discussed in Pissarides $(1979,1984)^{3}$.Modern macroeconomics is being divided by primarily two schools of thought: Real Business Cycle theory that follows classical tradition, for which expansions and recessions are efficient response the technological state of the economy, and New Keynesian economics which states that economies are prone to market failures, and that government could have a role in improving these market conditions, see Celso J. Costa (2016). Imperfect competition is at the heart of the New Keynesian model and this model primarily was developed by: Rotemberg (1982), Blanchard and Kiyotaki (1987), Rotemberg and Woodford (1997). In this sense Akerlof (1970), pointed out that a host of market imperfection phenomena best understood as response to imperfect and asymmetric information. model includes labor disutility. But it also does include unlike RBC model: new Keynesian Philips Curve, forward term, substitutability/mark-up on prices, Monetary Policy Smoothing Parameter, Monetary Policy GDP Growth target, and monetary policy inflation target. Fair pricing and fair wages also were included in the theoretical part of this paper. Rotemberg (2005) developed the first theory of price rigidity based on fairness considerations, but he was using the social-preference approach by: Rabin (1993) and Fehr,Schmidt (1999).In the fair pricing model that is explained in this paper, that is a model by Eyster, Madarsz, Michaillat (2019),consumers fail to savor unfairly priced goods, they are not demanding those products irrespective whether it harms the firm. So this paper is organized as follows: First Monetary policy effectiveness is explained in the model of Akerlof (1985), then we proceed to explain equilibrium Unemployment, then we proceed to explain social norms model and unemployment as consequence, Akerlof (1980) model, and model of fair wages or Akerlof (1982) model. Then we move to Eyster, Madarsz, Michaillat (2019) model of fair pricing in Monopoly model and New Keynesian setting. Then finally we move into explaining whole this system as a whole in a Dynamic Stochastic General Equilibrum framework in MATLAB by using a code written by Gauthier Vermandel and published on his research page. These models are all about "macroeconomists' adherence to

\footnotetext{
${ }^{1}$ Tobin (1972) asserted that the now job seeking theory of Phelps et.al. (1970), is useful in explaining the voluntary frictional unemployment. But in the Beveridge curve reality -"vacancies should not be less than unemployment. But because of limited capital stocks and interdependence among skills, jobs cannot be indefinitely multiplied without lowering their marginal productivity". ..”Our wise and benevolent planner would not place people in jobs yielding less than the marginal value of leisure. Given this constraint on the number of jobs, he would always have to keep some workers waiting, and some jobs vacant"..wrote Tobin (1972) acknowledging that there must be involuntary unemployed workers.

${ }^{2}$ Barron (1975) wrote:" It becomes clear that the expected duration of unemployment entails more than a comparison of an acceptance wage and the wage offer distribution". He pointed out that papers such as Mortensen (1970a), "assumed a constant probability of receiving a wage offer each period".

${ }^{3}$ Despite its importance there are very few attempts to derive the matching function from primitive assumptions that labor market is a place of trade .Hall (1979), Pissarides (1979), and Blanchard and Diamond (1994) have borrowed Butters's (1976) urn problem (probability picking a ball from an urn) game to derive an exponential function.
} 
one-deviation-at-a-timism, and their antipathy to multiple beauty-contest equilibria", Akerlof (2019).

\section{Monetary policy effectiveness}

Here we are explaining in short Akerlof (1985), model:

Equation 1

$$
X=\left(\frac{p}{\bar{p}}\right)^{-\eta}\left(\frac{M}{\bar{p}}\right) \eta>1
$$

Where: $X$-output of the firm; $p$-price of the firm of the output, $\bar{p}$-the average price level , $M$ the money supply per firm. $\eta>1$ so that each firm has increasing revenue as price falls $\bar{p} X=$ $M$. In long run previous expression holds. Production function by which firms produce output is given as:

Equation 2

$$
X=(e N)^{\alpha} ; 0<\alpha<1
$$

Where $e$-effort ; $N$-numbers of laborers hired .Relationship between effort and laborers is given as : $e N=X^{\frac{1}{\alpha}} \Rightarrow N=\frac{X^{\frac{1}{\alpha}}}{e} ; e=e(w)$. Here $e(w)$ is assumed to be a function like $: e(w)=-a+b w^{\gamma} ; 0<\gamma<1, a>0 ; b>0$. Profits of the firms are equal to:

Equation 3

$$
\Pi=p\left(\frac{p}{\bar{p}}\right)^{-\eta} \frac{M}{\bar{p}}-\left(\frac{p}{\bar{p}}\right)^{-\frac{\eta}{a}}\left(\frac{M}{\bar{p}}\right)^{\frac{1}{\alpha}} w(e(w))^{-1} \bar{p}
$$

Equilibrium condition at the initial price $P_{0}$ is given as : $p_{o}=k \bar{M}_{0}$. In the previous equation: $\bar{M}_{0}$-initial money supply $p_{o}$-initial price level .Also in previous equation $k$ is equal to: Equation 4

$$
k=\left(\frac{\eta w^{*}}{\alpha(\eta-1) e\left(w^{*}\right)}\right)^{\frac{\alpha}{1-\alpha}}
$$

Where $w^{*}$-optimal level of wage (Solow wage elasticity of effort with respect to wage is unity and represents the condition by which firm chooses the real wage that minimizes the unit cost of labor efficiency unit). The demand for labor now is: $N_{0}=\frac{k^{1-\alpha}}{e\left(w^{*}\right)}$. Total supply of labor $\bar{L}$ now exceeds the total demand for labor. In this case there will be unemployment, so the firm will be able to obtain all the labor that is needed by the preferred wage rate $w^{*}$.Money supply changes by a fraction $\epsilon$

Equation 5

$$
M=M_{0}(1+\epsilon)
$$

$m$-firms are short maximizers and set prices of their output and wage at the levels that exactly maximize profits on the assumption that the average price level is unaffected by their decisions. The $n$-firms which continue a rule of thumb, continue to charge the same price of output and to pay the same wage. Money wages are sticky over business cycles, and also that prices are constant markup over normal average unit costs. Now the key endogenous variables in the short-run equilibrium are given as: 
Table 1 Key endogenous variables in near-ration model of Akerlof (1985)

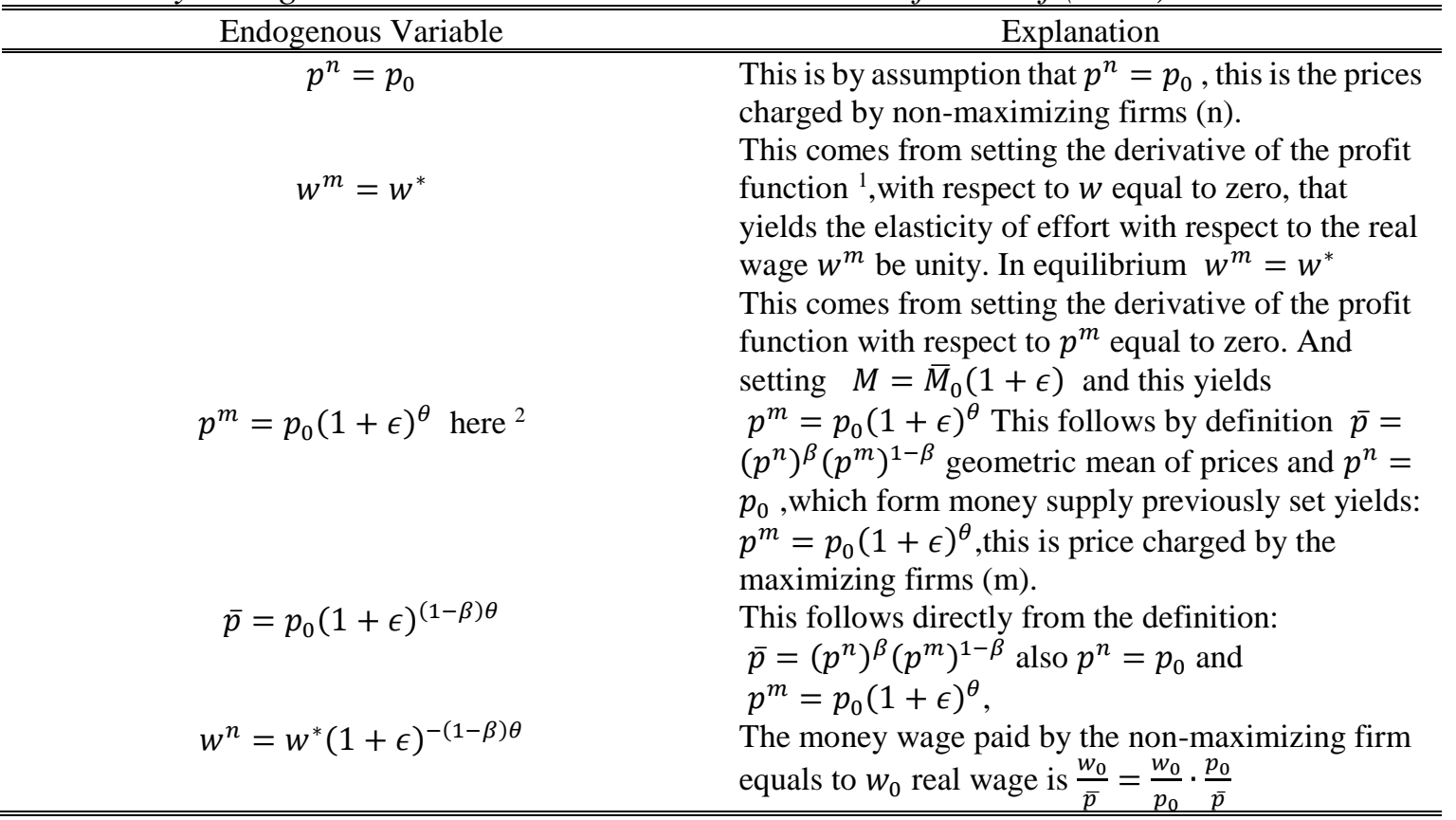

\section{Source: Akerlof (1985)}

Profit function of the non-maximizing and maximizing function are given as;

\section{Equation 6}

$$
\begin{gathered}
\Pi^{n}=\left(p_{0}\right)^{1-\eta} f(\epsilon)-\left(p_{0}\right)^{-\eta \alpha} g(\epsilon) h(\epsilon) w^{*}\left[e\left(h(\epsilon) w^{*}\right)\right]^{-1} \\
\Pi^{m}=\left(p^{m}(\epsilon)\right)^{1-\eta} f(\epsilon)\left(p^{m}(\epsilon)\right)^{-\eta \alpha} g(\epsilon) w^{*}\left(e\left(w^{*}\right)\right)^{-1}
\end{gathered}
$$

$g(\epsilon)$ and $f(\epsilon)$ unimportant can be calculated explicitly by substituting $\bar{p}=p_{0}(1+\epsilon)^{(1-\beta) \theta}$ and $M=M_{0}(1+\epsilon)$ for $\bar{p}$ and $M$ in the profit function. Similarly, $h(e)$ equals to : $h(\epsilon)=$ $(1+\epsilon)^{-(1-\beta) \theta}$ since $: w^{n}=w^{*}(1+\epsilon)^{-(1-\beta) \theta} ; h(0)=1$ which is a property of $h(e)$. The derivative of $\Pi^{n}-\Pi^{m}$ with respect to $\epsilon$ is given as:

\section{Equation 7}

$$
\begin{aligned}
\frac{d\left(\Pi^{m}-\Pi^{n}\right)}{d \epsilon}= & \left\{(1-\eta) p^{m}(\epsilon)^{-\eta} f(\epsilon)+\left(\frac{\eta}{\alpha}\right) \times\left(p^{m}(\epsilon)\right)^{-\frac{\eta}{\alpha-1}} g(\epsilon) w^{*}\left(e\left(w^{*}\right)\right)^{-1}\right\} \frac{d p^{m}}{d \epsilon} \\
& +\left\{w ^ { * } \left[e\left(h(\epsilon) w^{*}\right]^{-1}-h(\epsilon) w^{* 2} e^{\prime}\left(h(\epsilon) w^{*}\right) \times\left[e\left(h(\epsilon) w^{*}\right]^{-2}\right\}\right.\right. \\
& \cdot \frac{d h}{d \epsilon}\left(p_{0}\right)^{-\left(\frac{\eta}{\alpha}\right)} g(\epsilon)+\left\{\left(p^{m}(\epsilon)^{1-\eta} f^{\prime}(\epsilon)-\left(p^{m}(\epsilon)\right)^{-\frac{\eta}{\alpha}} w^{*}\left[e\left(w^{*}\right)\right]^{-1} g^{\prime}(\epsilon)\right\}\right. \\
& -\left\{\left(p_{0}\right)^{1-\eta} f^{\prime}(\epsilon)-\left(p_{0}\right)^{-\frac{\eta}{\alpha}} h(\epsilon) w^{*}\left[e\left(h(\epsilon) w^{*}\right)\right]^{-1} g^{\prime}(\epsilon)\right\}
\end{aligned}
$$

For $\epsilon=0$ it follows that $\left.\frac{d\left(\Pi^{m}-\Pi^{n}\right)}{d \epsilon}\right|_{\epsilon=0}=0$.That was for the profit maximization. Now for the employment the elasticity of the employment with respect to changes of the money supply is non-zero. But for $\epsilon=0$ this elasticity is given as:

\footnotetext{
${ }^{1}$ Profit function was previously defined to be $: \Pi=p\left(\frac{p}{\bar{p}}\right)^{-\eta} \frac{M}{\bar{p}}-\left(\frac{p}{\bar{p}}\right)^{-\frac{\eta}{a}}\left(\frac{M}{\bar{p}}\right)^{\frac{1}{\alpha}} w(e(w))^{-1} \bar{p}$

${ }^{2} \theta=\frac{(1-\alpha) \alpha}{\beta\left(\frac{\eta}{\alpha-\eta+1}\right)+(1-\beta)\left(\frac{1-\alpha}{\alpha}\right)} \leq 1$
} 


\section{Equation 8}

$$
\frac{d\left(\frac{N}{N_{0}}\right)}{d \epsilon}=\frac{1}{\alpha}(1-(1-\beta) \theta)+\beta(1-\beta) \theta
$$

Since $\theta<1$ increase in money supply causes increase in employment.Or if we substitute $N=\frac{X^{\frac{1}{\alpha}}}{e} ; w^{n}=w^{*}(1+\epsilon)^{-(1-\beta) \theta}$ and $N_{0}=\frac{k^{1-\alpha}}{e\left(w^{*}\right)}$, and divide $\frac{N}{N_{0}}$ we get :

Equation 9

$$
\frac{X^{\frac{1}{\alpha}} W^{*}}{k^{1-\alpha}}=\frac{\left(\frac{X^{\frac{1}{\alpha}} w^{n}}{(1+\epsilon)^{-(1-\beta) \theta}}\right)}{k^{1-\alpha}}=\frac{w^{*}(1+\epsilon)^{-(1-\beta) \theta} X^{\frac{1}{\alpha}}}{\left(\frac{\bar{p}}{(1+\epsilon)^{(1-\beta) \theta}}\right)^{1-\alpha}} \Rightarrow \frac{d\left(\frac{N}{N_{0}}\right)}{d \epsilon}
$$

For $\theta=1$ and $\beta=0$ the model goes to money neutrality. Any deviation form profit maximizing price is second order to the firms. But firms adjust prices slowly following a change in money supply. But the changes of the money supply change real balances by $\left(\frac{M}{P}\right)$ by a first-order amount, which cause first order changes on output and employment. Which means that monetary policy is effective ${ }^{1}$. Next it is shown profit maximizing pricing behavior of the firms. So, for the firm that has any market power their profits will be flat in the neighborhood of their optimum own price. Any deviation from the profit maximization prices causes small loss in profit, Akerlof (2001).

\section{Figure 1 Profit maximization price}

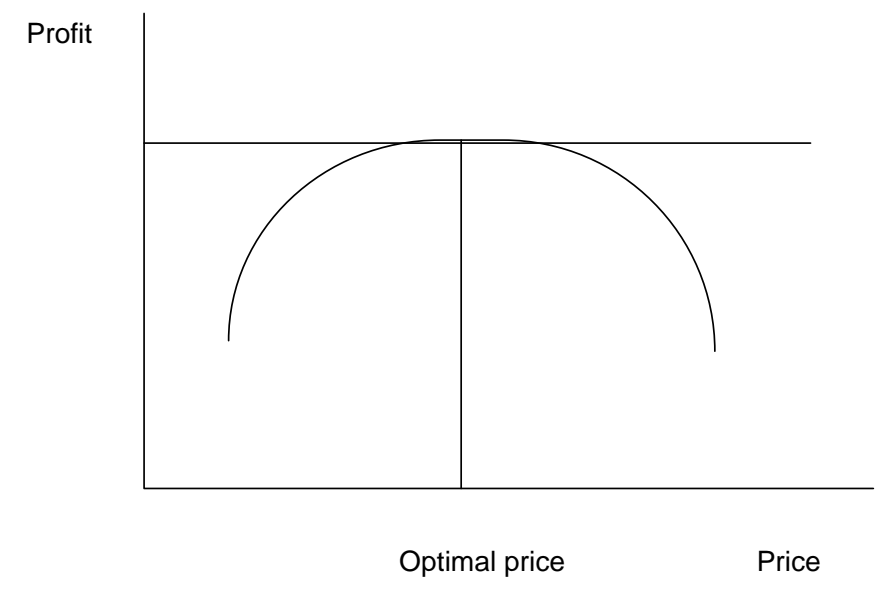

\section{Equilibrium Unemployment}

In this part we are explaining several reasons of unemployment: first are search and matching models with stochastic job matching. This literature draws primarily on: Alchian (1969), Phelps (1968), and Mortensen (1970); and Phelps et al. 1970. The driving impetus to this research came from Phelps's (1967) and Friedman's (1968) reappraisal of the Phillips curve and the natural rate approach to which this led, see Pissarides (2000). The endogenous job destruction model is based on Mortensen and Pissarides (1994), Labor force participation in the context of

\footnotetext{
${ }^{1}$ Let's suppose that money supply changes by the fraction $\epsilon$, the losses for the non-profit maximizing firms are square of $\epsilon$, so if $\epsilon=0.5$ losses are $\epsilon^{2}=0.0025$. So monetary policy is effective when pricing of the firms is near rational.
} 
a job-matching model was considered by McKenna (1987). The fact that when there is search on the job the optimal policy can be described by two reservation wages was first noted in a partial context by Burdett (1978). Vacancy chains caused by quitting are studied by Contini and Revelli (1997) and Akerlof, Rose, and Yellen (1998). Stochastic job matchings were first analyzed by Jovanovic (1979) in a partial model of labor turnover.On the model of the effects of the policy : An early exception is the paper by Diamond (1981), which considered unemployment compensation as a policy to correct the inefficiencies introduced by the externalities in the model. Matching function model is given as $m L=m(u L, v L)$. This function is concave and homogenous of degree 1 . Homogeneity or constant returns to scale. Where $u$ is unemployment rate, $v$-vacancy rate, $u L$ unemployed worker L-total labor force, and vL job vacancies. Vacancy to filled jobs equals v/u is denoted to $\theta$ and equals to: $\theta=m(u / v, 1), \delta t$ is a small time intervak during some vacant job is matched to an unemployed person,with a probability $q(\theta) \delta t$. To a related Poisson process $\lambda=\frac{m(u L, v L)}{u L}$ where $\lambda=\theta q(\theta)$ and has elasticity $1-\eta(\theta) \geq 0$. The mean duration of unemployment is $1 / \theta q(\theta)$. Worker goes from employment to unemployment with probability $\lambda \delta t$, the mean number of workers who enter unemployment during a small time interval is $\lambda(1-u) L \delta t$, and the mean number who leave unemployment is $m L \delta t$,pr we can rewrite the latter as: is $u \theta q(\theta) L \delta t$, where $\theta q(\theta) \delta t$ is the transitional probability of unemployed. The evolution of mean unemployment is given as: $\dot{u}=$ $\lambda(1-u)-\theta q(\theta) u$. In the steady-state the mean rate of unemployment is given as: $\lambda(1-u)=$ $\theta q(\theta) u$. The equation that determines unemployment in terms of two transition states is: $u=$ $\frac{\lambda}{\lambda+\theta q(\theta)}$. Job creation rate is defined as the ratio of the number of jobs created to employment $\frac{m(v, u)}{1-u}$, and job destruction rate is similarly defined as the ratio of the total number of jobs destroyed to employment $\frac{\lambda(1-u)}{1-u}$ Let $J$ be the present-discounted value of expected profit from an occupied job and $V$ the present-discounted value of expected profit from a vacant job. With a perfect capital market, an infinite horizon and when no dynamic changes in parameters are expected, $\mathrm{V}$ satisfies the Bellman equation $: r V=-p c+q(\theta)(J-V)$.A job is an asset owned by the firm. In a perfect capital market the valuation of the asset is such that the capital cost, $r V$, is exactly equal to the rate of return on the asset: The vacant job costs $p c$ per unit time and changes state according to a Poisson process with rate $q(\theta)$. The equilibrium condition for the supply of vacant jobs is $V=0$, implying that: $J=\frac{p c}{q(\theta)}$. Let $U$ and $W$ denote the presentdiscounted value of the expected income stream of, respectively, an unemployed and an employed worker, including the imputed return from nonmarket activities. The unemployed worker enjoys (expected) real return $z$ while unemployed, and in unit time he expects to move into employment with probability $\theta q(\theta)$. Hence $U$ satisfies $r U=z+\theta q(\theta)(W-U), r U$ can be given two useful interpretations. First it is the average expected return on the worker's human capital during search, it is the minimum compensation that an unemployed worker requires to give up search (reservation wage). Employed workers earn a wage $w$; they lose their jobs and become unemployed at the exogenous rate it. Hence the valuation placed on them by the market, $W$, satisfies $r W=w+\lambda(U-W)$. Without on-the-job search, workers stay in their jobs for as long as $\mathrm{W} \geq \mathrm{U}$. the permanent incomes of unemployed and employed workers, in terms of the returns $z$ and $w$ and the discount and transition rates:

Equation 10

$$
r U=\frac{(r+\lambda) z+\theta q(\theta) w}{r+\lambda+\theta q(\theta)} ; r W=\frac{\lambda z+[r+\theta q(\theta)] w}{r+\lambda+\theta q(\theta)}
$$

The job is worth to the worker : $r W_{i}=w_{i}-\lambda\left(W_{i}-U\right)$ the job rate for this job satsfies : $w_{i}=$ $\operatorname{argmax}\left(W_{i}-U\right)^{\beta}\left(J_{i}-V\right)^{1-\beta}$, where $\beta$ is labor's share of the total surplus that an occupied 
job creates, $\beta=\frac{1}{2}$ is the most plausible value. $\beta=\frac{1}{2}$ is the most plausible value. Wage function now is: $w_{i}=r U+\beta(p-r)$, where $r U$-reservation wage, $\beta(p-r)$ fraction of net surplus they create by accepting the job, product value net of what they give up, $r U, r U=z+\frac{\beta}{1-\beta} p c \theta$.And the aggregate wage equation that holds in equilibrium, $w=(1-\beta) z+\beta p(1+c \theta)$.It is intuitive for a market equilibrium if we note that $p c \theta$ is the average hiring cost for each unemployed worker (since $p c \theta=p c v / u$ and $p c v$ is total hiring cost in the economy). if we let $z=\rho w$, where $\rho$ is the replacement rate (a policy parameter), then the wage equation becomes: $w=\frac{\beta(1+c \theta)}{1-(1-\beta) \rho} p$. With capital $w=(1-\beta) z+\beta p(f(k)-(r+\delta) k+c \theta)$ is the aggregate wage equation that holds in equilibrium. With the out of steady state dynamics the value of vacant and filled job are becoming:

\section{Equation 11}

$r V=-p c+\dot{V}+q(\theta)(J-V) ; r J=p-w+j-\lambda J$

In the asset value of a vacant job, expected capital gains from changes in the valuation of the asset $\dot{V}$, yield $-p c$ and expected capital gains from the chance of finding a worker to take the vacancy $q(\theta)(J-V)$.In the value of the filled job equation $\dot{J}$ - is the expected capital gain from changes in job value during adjustment.Our assumption that firms exploit all profit opportunities from new jobs, regardless of whether they are in the steady state or out of it, implies that $V=\dot{V}=0 . J=\frac{p c}{q(\theta)} ; j=(r+\lambda) J-(p-w)$. The arbitrage equations when changes in valuations take place because of out-of-steady-state dynamics are

\section{Equation 12}

$$
r U=z+\dot{U}+\theta q(\theta)(W-U) ; r W=w+\dot{W}+\lambda(U-W)
$$

In the endogenous job destruction model, The asset value of a job with productivity in the range $1 \geq x \geq R$ satisfies $: r J(x)=p x-w(x)+\lambda \int_{R}^{1} J(s) d G(s)-\lambda J(x)$. For the worker the returns from working at a job with idiosyncratic productivity $x$ satisfy

Equation 13

$$
r W(x)=w(x)+\lambda \int_{R}^{1} W(s) d G(s)+\lambda G(R) U-\lambda W(x)
$$

The reservation productivity $R$, is defined by: $J(R)=0$. By the reservation property, firms destroy all jobs with idiosyncratic productivity $x<R$ and continue producing in all jobs with productivity $x \geq R$. Therefore the flow into unemployment (job destruction) is given by $\lambda(R)(1-u)$. As before, the flow out of unemployment is equal to job creation, $m(v, u)=$ $\theta q(\theta) u$. The evolution of unemployment is therefore given by $\dot{u}=\lambda G(R)(1-u)-\theta q(\theta) u$. And its steady-state value is given by:

\section{Equation 14}

$$
u=\frac{\lambda G(R)}{\lambda G(R)+\theta q(\theta)}
$$

For the analysis of additive shifts, we suppose that all idiosyncratic productivities $x$ depend on an additive shift parameter $h$, such that $: x(h)=x+h$ Thus, in examining the effects of a change in the variability of the productivity distribution, we write: $x(h)=x+h(x-\bar{x}) ;(1-\beta)(1+h) \frac{1-R}{r+\lambda}=\frac{c}{q(\theta)}$ $;(1+h) R-h \bar{x}+\frac{(1+h) \lambda}{r+\lambda} \int_{R}^{1}(s-r) d G(s)=\frac{z}{p}+\frac{\beta}{1-\beta} c \theta$

Wage equation here is given as: $w(x)=(1-\beta) z+\beta p(x+c \theta)$ where, Equation 15

$$
\begin{gathered}
(r+\lambda) J(x)=(1-\beta)(p x-z)-\beta p c \theta+\lambda \int_{R}^{1} J(s) d G(s) . \\
(r+\lambda) J(x)=(1-\beta) p(x-R) .
\end{gathered}
$$




\section{Equation 16}

$$
(r+\lambda) J(x)=(1-\beta)(p x-z)-\beta p c \theta+\frac{\lambda(1-\beta) p}{r+\lambda} \int_{r}^{1}(s-R) d G(s) .
$$

the expected gain from a new job to the firm must be equal to the expected hiring cost that the firm has to pay are given as: $(1-\beta) \frac{1-R}{r+\lambda}=\frac{c}{q(\theta)}$, if we let $z=\rho w$, where $\mathrm{p}$ is the replacement rate (a policy parameter), then the wage equation becomes: $w=\frac{\beta(1+c \theta)}{1-(1-\beta) \rho} p$. Now in the out of steady-state dynamics, as before, $U$ denotes the net worth of an unemployed worker and $W$ the net worth of an employed worker. The arbitrage equations when changes in valuations take place because of out-of-steady-state dynamics are ${ }^{1}: r U=z+\dot{U}+\theta q(\theta)(W-U) ; r W=w+$ $\dot{W}+\lambda(U-W)$. Thus, in examining the effects of a change in the variability of the productivity distribution, we write

\section{Equation 17}

$$
\begin{aligned}
x(h)=x+ & h(x-\bar{x})(1-\beta)(1+h) \frac{1-R}{r+\lambda}=\frac{c}{q(\theta)} \\
& (1+h) R-h \bar{x}+\frac{(1+h) \lambda}{r+\lambda} \int_{R}^{1}(s-r) d G(s)=\frac{z}{p}+\frac{\beta}{1-\beta} c \theta
\end{aligned}
$$

Differentiation with respect to $h$, however, shows that at $h=0$ both market tightness and the reservation productivity rise. Differentiation of previous gives

$$
\left[1-\frac{\lambda}{r+\lambda}[1-G(R)]\right] \frac{\partial R}{\partial h}=\bar{x}-R-\frac{\lambda}{r+\lambda} \int_{R}^{1}(s-R) d G(s)+\frac{\beta}{1-\beta} c(\partial \theta / \partial h)
$$

Differentiation with respect to $h$

\section{Equation 18}

Elasticity notation

$$
\frac{c \eta(\theta)}{\theta q(\theta)} \frac{\partial \theta}{\partial h}=\frac{1-\beta}{r+\lambda}\left[1-R-\frac{\partial R}{\partial h}\right]
$$

\section{Equation 19}

$$
\eta(\theta)=-\frac{\partial q(\theta)}{\partial \theta} \frac{\theta}{q(\theta)}
$$

$$
\begin{gathered}
{\left[1-\frac{\lambda}{r+\lambda}[1-G(R)]\right](1-R)-\bar{x}+R+\frac{\lambda}{r+\lambda} \int_{R}^{1}(s-R) d G(s)} \\
1-\bar{x}-\frac{\lambda}{r+\lambda} \int_{R}^{1}(1-s) d G(s) ; 1-\bar{x}=\int_{0}^{1}(1-s) d G(s) \\
\bar{x}-R-\frac{\lambda}{r+\lambda} \int_{R}^{1}(s-R) d G(s)+\frac{\beta}{(1-\beta) \eta(\theta)} c \theta
\end{gathered}
$$

Similarly, for given market tightness, the higher interest rate reduces the option value of the job, and so the reservation productivity is higher. The effect of these shifts on market tightness is unambiguously negative, but it is ambiguous on the reservation productivity. To see this, differentiate with respect to $r$ to get $: \frac{c \eta(\theta)}{\theta q(\theta)} \frac{\partial \theta}{\partial h}=\frac{1-\beta}{r+\lambda}\left[1-\frac{R}{r+\lambda}-\frac{\partial R}{\partial r}\right]$, the reservation productivity

\footnotetext{
${ }^{1} z=\frac{\rho \beta}{1-\rho(1-\beta)} p[E(x \mid x \geq R)+c \theta]$; Unemployment income is proportional to the general productivity parameter, $p$. Substitution of $\mathrm{z}$ gives the new job destruction condition: $R-\frac{\rho \beta}{1-\rho(1-\beta)}(E(x \mid x \geq R))-\frac{\beta}{1-\beta} \frac{c \theta}{1-\rho(1-\beta)}+$ $\frac{\lambda}{r+\lambda} \int_{R}^{1}(s-R) d G(s)=0$
} 
is independent of labor's share, and the net effect of labor's share on market tightness becomes $: \frac{\partial \theta}{\partial \beta}=-\frac{\theta}{(1-\beta) \eta}$. In the endogenous job creation with capital, reservation productivity $R$, defined by $J(R)=0$. By the reservation property, firms destroy all jobs with idiosyncratic productivity $x<R$ and continue producing in all jobs with productivity $x \geq R$. Therefore the flow into unemployment (job destruction) is given by $\lambda(R)(1-u)$. As before, the flow out of unemployment is equal to job creation, $m(v, u)=\theta q(\theta) u$. The evolution of unemployment is therefore given by: $\dot{u}=\lambda G(R)(1-u)-\theta q(\theta) u^{1}$. Job creation and job destruction conditions, wage sharing rule gives the following equation

Equation 20

$$
\begin{gathered}
w(x)=(1-\beta) z+\beta p x[f(k)-(r+\delta) k]+\beta p c \theta \\
(r+\lambda) J(x)=(1-\beta) p(x-R)[f(k)-(r+\delta) k] \\
(r+\lambda) J(x)=(1-\beta) p[f(k)-(r+\delta) k]\left[x+\frac{\lambda}{r+\lambda} \int_{R}^{1} \frac{(s-R)}{1-R} d G(s)\right]-(1-\beta) z-\beta p c \theta
\end{gathered}
$$

The job creation condition, which as before satisfies, is derived from, and it is : $(1-\beta) \frac{1-R}{r+\lambda}[f(k)-$ $(r+\delta) k]=\frac{c}{q(\theta)}$. The job destruction condition is derived from

Equation 21

$$
[f(k)-(r+\delta) k]\left[R+\frac{\lambda}{r+\lambda} \int_{R}^{1}(s-R) d G(s)\right]=\frac{z}{p}+\frac{\beta}{1-\beta} c \theta
$$

Aggregate capital in this economy is $: K=L(1-u) p k \int_{R}^{1} x d G(x)$ and aggregate output $F(L(1-u), K)$, or in per unit terms $: Y=L(1-u) p f(k) \int_{R}^{1} x d G(x)$. And now, with labour force participation the model becomes : When workers are out of the labor force, they enjoy leisure worth $l_{0}$, in real terms, which they lose when they enter the market. Formally, we assume that it is a drawing from a distribution with cumulative density $H\left(l_{0}\right)$. With $z=0$

\section{Equation 22}

$U=\frac{\theta q(\theta) w}{r[r+\lambda+\theta q(\theta)]} ; U_{0}=\frac{l_{0}}{r}$

Consider a household which has nonhuman wealth $A$ and no members in the labor force. We assume that the utility that a typical member of the household derives from nonparticipation is proportional to the permanent flow of income derived from household wealth: $l_{0}=\operatorname{lr} A$ cdf $H(l): l_{o}=l_{r}(A+W)$. A non-human wealth $\mathrm{W}$ is human wealth (present discounted value of income from employment) Finally, if a household has one unemployed participant and no employed members,its wealth is $A+U$, with $U$ given by (1.12) or (7.1), so the utility of a nonparticipating member is $: l_{o}=l_{r}(A+U)$. One in a household with an unemployed participant will have, $l_{r}=\frac{U}{A+U} ; \frac{U}{W}=\frac{\theta q(\theta)}{r+\theta q(\theta)}<1$. Hence the two equations giving the worker's present-discounted utility during unemployment and during employment in some job $j$ are, respectively, $r U=\theta q(\theta)(W-U) \quad ; r W_{j}=w_{j} h_{j} \phi\left(1-h_{j}\right)+\lambda\left(U-W_{j}\right)$. Hence optimum hours satisfy

Equation 23

$$
\frac{\phi^{\prime}\left(1-h_{j}\right)}{\phi\left(1-h_{j}\right)} h_{j}=1
$$

\footnotetext{
${ }^{1}$ The value of a job with idiosyncratic productivity parameter $x$ now satisfies ; $r[J(x)+p x k]=$ $p x[f(k)-\delta k]-w(x)+\lambda \int_{R}^{1} J(s) d G(s)-\lambda J(x) ; f^{\prime}(k)=r+\delta$
} 
Let $p$ be the product per hour input. Then, the present-discounted value of profit from a vacant job and from a filled job $j$ are, respectively ${ }^{1}$,

\section{Equation 24}

$r V=-p c+q(\theta)(J-V) ; r J_{j}=h_{j} p-h_{j} w_{j}-\lambda J_{j} ;\left(W_{j}-U\right)^{\beta}\left(J_{j}-V\right)^{1-\beta}$

Wage equation here is : $w=\beta p\left(1+\frac{c}{h} \theta\right)$.And now about Labor Turnover and On-the-Job

Search, We begin by introducing three new labor flows into the job creation and job destruction model: , which are modeled as jump processes with constant exogenous rate: entry into the labor force taking place at rate $b$ (for births), exit from the labor force at rate $d$ (for deaths), and quitting into unemployment to look for another job at rate $\lambda_{0}$. As before, we assume that there is a jump process that shocks idiosyncratic productivity at rate $\lambda$. This leads to job destruction and a flow into unemployment of $\lambda G(R)(1-u) L$ workers, with $L$ denoting the total labor force. In addition there is now a flow of new entrants $b L$ into unemployment and quits $\lambda_{0}(1-u) L$. The exits from unemployment are the retirements, $d u L$, and the total matches of unemployed workers with vacant jobs which we write, as previously, as $q(\theta) \theta u L$ Total unemployment is given by $u L$, so its evolution is given by: $\frac{d}{d t} u L=\left[\lambda G(R)+\lambda_{0}\right](1-u) L+$ $b L+d u L-q(\theta) \theta u L^{2}$.The rate of growth of labor force $\frac{\dot{L}}{L}$ id given by the total entry less total exit, $b-d$, and now the equation of the evolution of unemployment is given as: $\dot{u}=$ $\left[\lambda G(R)+\lambda_{0}+b\right](1-u)-q(\theta) \theta u$. The steady state level of unemployment derived from previous is

Equation 25

$$
\dot{u}=\frac{\lambda G(R)+\lambda_{0}+b}{\lambda G(R)+\lambda_{0}+b+q(\theta) \theta u}
$$

The value of a vacant job is given, as before, by : $r V=-p c+q(\theta)[J(V)-V]$. About the search on the job, If unemployment is again $u$, vacancies $v$ and the number of employed job seekers is denoted by $e \leq 1-u$, we write the aggregate matching function as : $m=$ $m(v, u+e)$.Under the assumption of constant returns to scale, the rate at which workers arrive to vacancies is a function of the ratio of vacancies to all job seekers. We use the same notation as before, $q(\theta) \equiv m\left(1, \frac{u+e}{v}\right)$ but with $\theta$ now denoting the ratio $\frac{v}{u+e}$. The approach that we follow in order to find the optimal search strategy is to calculate the worker's returns for each productivity $\mathrm{x}$ when he is and when he is not searching on the job. Let the former be $W^{\prime}(x)$ and the latter $W^{\prime \prime \prime}(x)$. Then search on the job takes place at productivity $\mathrm{x}$ when $W^{s}(x) \geq W^{n s}(x)$. Trivially, at maximum productivity, search on the job is not optimal, $W^{s}(1) \leq W^{n s}$. The reservation productivity, if it exists, satisfies : $W^{s}(S) \geq W^{n s}(S)$. To avoid trivial outcomes for search on the job, we assume that the cost $\sigma$ is sufficiently small to imply that if there is a reservation rule defined by $S$, then $S>R$. But first we need to demonstrate that the reservation rule exists, namely that $W^{s}(x)-W^{n s}(x)$ decreases in $x$. The expected returns of the employed worker when he does and when he does not search respectively satisfy

\footnotetext{
${ }^{1}$ The wage rate that maximizes previous satisfies the condition : $\beta\left(J_{j}-V\right) \phi\left(1-h_{j}\right)-(1-\beta)\left(W_{j}-U\right)=0$. Hours of work also maximize, and the condition they satisfy is $\beta\left(J_{j}-V\right) w_{j} \phi\left(1-h_{j}\right)\left(1-\frac{\phi^{\prime}(.)}{\phi(.)} h_{j}\right)+(1-\beta)\left(W_{j}-U\right)\left(p-w_{j}\right)=0 ; J=$ $\frac{p c}{q(\theta)} ; h(p-w)-\frac{r+\lambda}{q(\theta)} p c=0$ where $W-U=\frac{w h \phi(1-h)}{r+\lambda+\theta q(\theta)}$

${ }^{2}$ The evolution of the unemployment rate is : $\dot{u}=\left[\lambda G(R)+\lambda_{0}\right](1-u)+b+d u-q(\theta) \theta u-\frac{u \dot{L}}{L}$
} 


\section{Equation 26}

$$
\begin{gathered}
r W^{s}(x)=w^{s}(x)-\sigma \\
+\lambda \int_{R}^{1} \max \left(W^{n s}(s), W^{s}(s)\right) d G(s)+\lambda G(R) U-\lambda W^{s}(x) \\
+\theta q(\theta)\left[W^{n s}(1)-W^{s}(x)\right] \\
r W^{n s}(x)=w^{n s}(x)+\lambda \int_{R}^{1} \max \left(W^{n s}(s), W^{s}(s)\right) d G(s)+\lambda G(R) U-\lambda W^{n s}(x)
\end{gathered}
$$

Now in the equilibrium The evolution of the number of job seekers $e$ is given as: $\dot{e}=$ $\lambda(1-u)[G(s)-G(R)]-\lambda e-\theta q(\theta) e$. In the steady state $: e=\frac{\lambda[G(S)-G(R)]}{\lambda+\theta q(\theta)}(1-u) ; \dot{u}=$ $\lambda G(R)(1-u)-q(\theta) \theta u$.Vacancies are given by $: v=\theta(u+e)$. To derive the final equation, for the reservation $R$ we impose the job destruction condition $J^{S}(R)=0$.To simplify the notation, we denote the option value of the job by $\Lambda$ and write Equation 27

$$
\begin{gathered}
\Lambda=\lambda \int_{R}^{1} \max \left(J^{n s}(s), J^{s}(s) d G(s)=\lambda \int_{R}^{1} J^{s}(s) d G(s)+\lambda \int_{R}^{1} J^{n s}(s) d G(s)\right. \\
J^{n s}(x)=\frac{1-\beta}{r+\lambda} p(x-R)-\frac{1-\beta}{r+\lambda}\left(\frac{\beta}{1-\beta} p c \theta-\sigma\right) \\
\Lambda=\lambda(1-\beta) p\left(\frac{1}{r+\lambda+\theta q(\theta)} \int_{R}^{s}(s-R) d G(s)+\frac{1}{r+\lambda} \int_{S}^{1}(s-R) d G(s)\right) \\
-\frac{\lambda(1-\beta) p}{r+\lambda}\left(\frac{\beta}{1-\beta} c \theta-\frac{\sigma}{p}\right)(1-G(s)
\end{gathered}
$$

To find the effect of search costs on search on the job, we differentiate with respect to $\sigma$,so ${ }^{1}$ $: \frac{\partial S}{\partial \sigma}-\frac{\partial R}{\partial \sigma}=\frac{\partial S}{\partial \theta} \frac{\partial \theta}{\partial \sigma}-\frac{r+\lambda+\theta q(\theta)}{\theta q(\theta)} \frac{1}{p}$.Now about stochastic job matchings, the idea formalized in this chapter is that jobs and workers have many unobservable characteristics that can influence the productivity of a job match. Two vacant jobs may look the same to a worker before he searches the firms offering them; two workers may look the same to a firm before it screens them. But when the jobs and workers are brought together, one pair may be more productive than the other. The new feature now introduced is the ex post match specific heterogeneity. We refer to this extension of the model as stochastic job matchings. Because all firms and workers are ex ante identical, the reservation productivity $\alpha_{r}$ is common to all job-worker pairs. So if all productivities $\alpha \geq \alpha_{r}$ are accepted, the fraction of acceptable job contacts is

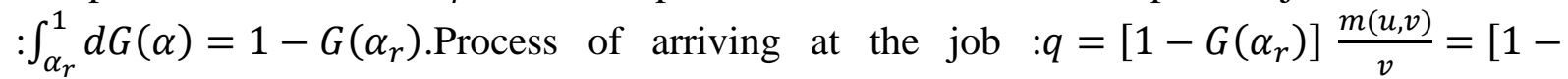
$\left.G\left(\alpha_{r}\right)\right] m$. Where $\left[1-G\left(\alpha_{r}\right)\right] m$ is the rate of job matching . and workers move from unemployment to employment at the rate $: q^{w}=\left[1-G\left(\alpha_{r}\right)\right] \frac{m(u, v)}{v}=\left[1-G\left(\alpha_{r}\right)\right] \theta q(\theta)$ .Unemployment rate is given as: $u=\frac{\lambda}{\lambda+\theta q(\theta)\left[1-G\left(\alpha_{r}\right)\right]}$.In general, the wage rate offered will depend on the productivity of the job match: $w_{j}=w\left(a_{j}\right): w_{r}=w\left(a_{r}\right)$ and $q_{i}^{w}=$ $\theta q(\theta)\left[1-G\left(\alpha_{r i}\right)\right]$.The net worth of unemployed worker $i$ and employed worker $j$ satisfies: $r U_{i}=z+q_{i}^{w}\left(W_{i}^{e}-U_{i}\right) \quad: \quad r W_{j}=w_{j}+\lambda\left(U_{i}-W_{j}\right)$.The reservation wage then becomes: $w_{r i}=\frac{(r+\lambda) z+q_{i}^{w} w_{i}^{e}}{r+\lambda+q_{i}^{w}} ; w_{r}=\frac{(r+\lambda) z+q^{w} w^{e}}{r+\lambda+q^{w}}$.In equilibrium following system of equations that holds:

${ }^{1}$ Where : $\frac{\partial S}{\partial \theta}=\frac{\beta c}{1-\beta}\left(1+\eta \frac{r+\lambda}{\theta q(\theta)}\right)+\frac{(1-\eta)(r+\lambda) \sigma / p}{\theta^{2} q(\theta)}>0$ 


\section{Equation 28}

$w_{e}=(1-\beta) z+\beta p\left(a^{e}+c \theta\right) ; u=\frac{\lambda}{\lambda+\theta q(\theta)\left[1-G\left(\alpha_{r}\right)\right]}$

$\alpha_{r}=\frac{z}{p}+\frac{\beta}{1-\beta} p c \theta \quad ;(1-\beta)\left(a^{e}-\frac{z}{p}\right)-\beta c \theta-\frac{(r+\lambda) c}{q(\theta)\left[1-G\left(\alpha_{r}\right)\right]}$

If we differentiate productivity versus $\frac{z}{p}$ we get: $\frac{\partial \alpha_{r}}{\partial z / p}=\frac{(r+\lambda) \eta(\theta)}{(r+\lambda) \eta(\theta)+\beta \theta q(\theta)\left[1-G\left(\alpha_{r}\right)\right]}$. Now about the effects of policy : We introduce the possibility of progressive or regressive taxation by assuming that if the gross wage at a job $j$ is $w_{j}$ the net wage received by the worker is $(1-t)\left(w_{j}+\tau\right)$. It is convenient to think of workers as receiving a tax subsidy $\tau$, and subsequently taxed on their total labor earnings, including the subsidy, at the proportional rate $t$. With this tax the net transfer from the worker to the tax authorities is: $T\left(w_{j}\right)=t w_{j}-$ $(1-t) \tau$. Marginal tax rate $0 \leq t \leq 1$. We will follow a simple approach to the modeling of hiring and firing taxes by assuming that the firm that hires a worker whose initial (general) productivity is $p$ receives a hiring subsidy of $p H$, and when the separation takes place, it has to pay a tax $p T$. exogenous. In those cases we define net unemployment benefit by $b=$ $\rho[p-T(p)]$.About the wage determination with policy following is true: $p-w-\frac{\left(r+\lambda_{p c}\right.}{q(\theta)}=0$ $w(1-\beta) z+\beta(1+c \theta) p$.The unemployed worker's net worth with policy is given by: $r U=z+b+\theta q(\theta)(W-U) ; r W_{j}=w_{j}-T\left(w_{j}\right)+\lambda\left(U-W_{j}\right)$. The firms net worth from a vacancy and from job paying $w_{j}$ are given by: $r V=-p c+q(\theta)(J+p H-V) ; r J_{j}=p+a-$ $w_{j}-\lambda\left(J_{j}+p F\right)$. Where hiring subsidy is $p H$, employment is subsidized at the rate $a$ per job, firing tax $p F$, tax subsidy $\tau$, the replacemet rate $\rho$,marginal tax rate $t$. Therefore the initial wage is chosen to maximize the product: $B_{0}=\left(W_{j}-U\right)^{\beta}(J-j+p H-V)^{1-\beta}$. But after the worker is taken on, the benefit to the firm from continuation of the contract is only $J_{j}$ since no further hiring subsidies are received. In contrast, now the firing tax becomes operational, and if the firm fails to agree to a continuation wage, its loss will be $J_{j}+p F$

Equation 29

$$
B\left(W_{j}-U\right)^{\beta}\left(J_{j}+p F-V\right)^{1-\beta}
$$

Following the terminology introduced in the literature by Lindbeck and Snower (1988), we refer to $w_{0 j}$, as the "outside" wage and to $w_{j}$ as the "inside" wage: $w_{0 j}$, is negotiated by those still outside the firm, before the firm gets locked in by turnover taxes, and $w_{j}$, is negotiated by those inside the firm, who benefit from the firing restrictions imposed on the firm. Given our assumptions, the outside (initial) wage solves : $\beta \frac{\partial W_{j}}{\partial w_{0 j}}\left(J_{j}+p H-V\right)+(1-\beta) \frac{\partial J_{j}}{\partial w_{0 j}}\left(W_{j}-\right.$ $U)=0$. and the inside (continuation) wage solves : $\beta \frac{\partial W_{j}}{\partial w_{0 j}}\left(J_{j}+p F-V\right)+(1-\beta) \frac{\partial J_{j}}{\partial w_{j}}\left(W_{j}-\right.$ $U)$. In the presence of taxes:

\section{Equation 30}

$\frac{\partial W_{j}}{\partial w_{0 j}}=\frac{\partial W_{j}}{\partial w_{j}}=\frac{1-T \prime\left(w_{j}\right)}{r+\lambda} ; \frac{\partial J_{j}}{\partial w_{0 j}}=\frac{\partial J_{j}}{\partial w_{j}}=-\frac{1}{r+\lambda}$

the outside and inside wage equations derived in equilibrium respectively are - that is, imposing $V=0$ and $w_{j}=w$ for all $\mathrm{j}-$ are:

Equation 31

$$
\begin{gathered}
w_{0}=\frac{1-\beta}{1-\rho(1-\beta)}\left[\frac{z}{1-t}-(1-\rho) \tau\right]+\frac{\beta}{1-\rho(1-\beta)}[(1+c \theta-\lambda F+(r+\lambda) H) p+a] \\
w=\frac{1-\beta}{1-\rho(1-\beta)}\left[\frac{z}{1-t}-(1-\rho) \tau\right]+\frac{\beta}{1-\rho(1-\beta)}[(1+c \theta-r F) p+a]
\end{gathered}
$$


the job destruction rule is:

\section{Equation 32}

$$
R+\frac{a+(1-\rho) \tau}{p}=\rho+r F-\frac{z}{p(1-t)}-\frac{\beta c}{1-\beta} \theta+\frac{\lambda}{r+\lambda} \int_{R}^{1}(s-R) d G(s)=0
$$

Now about the search of the job intensity, the rate at which jobs arrive becomes $: q_{i}^{w}=$ $\frac{s_{i}}{s_{u}} m(s, u, v), s_{i}$ efficiency units supplied by the worker, Here $s$ is the equilibrium search intensity supplied by the representative worker. The worker's cost of $s_{i}$ units of search is $\sigma_{i}=$ $\sigma\left(s_{i}, z\right)$. The equilibrium equation with policy is similar to the one without policy,

Equation 33

$s \sigma_{s}(s, z)=\frac{\beta(1-t)}{1-\beta} p c \theta ; \sigma\left(s_{i}, z\right)=z h(s)$

Where $h(s)$ are the number of hours devoted to search., $h^{\prime}(s)>0 ; h^{\prime \prime}(s) \geq 0 ; s z h^{\prime}(s)=$ $\frac{\beta(1-t)}{1-\beta} p c \theta$. In the stochastic job matchings case, the equation for reservation productivity now becomes: $\alpha_{r}=\frac{z}{p(1-t)}-\frac{a-(1-\rho) \tau}{p}+\rho+\frac{\beta}{1-\beta} c \theta$ where $(1-\beta)\left(\alpha^{e}+\frac{a-(1-\rho) \tau}{p}-\rho-\frac{z}{p(1-t)}\right)-$ $\beta c \theta-\frac{(r+\lambda) c}{q(\theta)}$. In the policy of compensating changes, $F=H$ (fired $=$ hired workers):

\section{Equation 34}

$a+(1-\rho) \tau-p \rho+r p F-\frac{z}{1-t}=-z ; a+\tau=-r p F+\frac{t}{1-t} z+\rho(p+\tau)$

Tax subsidy $\tau$ should be chosen to satisfy following: $\tau=\frac{\rho}{1-\rho} p \quad ; \tau=\frac{t}{1-t} z+\rho(p+\tau) ; \tau=$ $\frac{t z+b}{1-t}$, the net revenue raised by the government is, from $T=\left[t w^{e}-(1-t) \tau\right](1-u)-$ $u b$, where $w^{e}$ conditional expectation pre-tax wage $: T=t\left(w^{e}-z\right)(1-u)-b$ pre-tax wage rate for given $x$ is also :

\section{Equation 35}

$w(x)=(1-\beta)\left(\frac{z+b}{1-t}-\tau\right)+\beta(x+c \theta+r F)+\beta a ; w(x)=(1-\beta) z+\beta(x+c \theta)$

This model also includes search externalities:

\section{Equation 36}

$$
\begin{aligned}
\frac{a-(1-\rho) \tau}{p} & -\rho+r F-\frac{z}{p(1-t)}-\frac{\beta}{1-\beta} c \theta=-\frac{z}{p}-\frac{\eta}{1-\eta} c \theta-F+H-\frac{c}{(1-\beta) q(\theta)} \\
& =-\frac{c}{(1-\eta) q(\theta)}
\end{aligned}
$$

optimal hiring subsidy now is : $H=F+\left(\frac{1}{1-\beta}-\frac{1}{1-\eta}\right) \frac{c}{q(\theta)}$ with $a+\tau=\rho(p+\tau)+\frac{t}{1-t} z-$ $r p F+\left(\frac{\beta}{1-\beta}-\frac{\eta}{1-\eta}\right) c p \theta$ it follows that the reservation productivity $\mathrm{R}$ with policy intervention is higher than in the policy-free environment if: $a+(1-\rho) \tau-p \rho+r p F-\frac{z}{1-t}<-z ; a+$ $\tau<\frac{t z+b}{1-t}-r p F$, the effect on job creation is neutralized if hiring subsidies and firing taxes are chosen such that: $-\frac{d R}{r+\lambda}-F+H=0$.One basic model of search intensity(without policy effects) that follows Card-Chetty-Weber (2007). Worker receives wage $w$ if employed and with no risk of job destruction the value function for employment at wage $w$ is: $U(w)=\frac{w}{1-\beta}$. A worker who is unemployed chooses search intensity $s$ which is the probability of finding a job. Unemployment benefit that unemployed worker receives is $b$, and it is included in the value function for unemployment, also wage $w$ is included for when the worker finds a job:

Equation 37

$$
V(b, w)=\max _{s}\{b+\beta[s U(w)+(1-s) V(b, w)-\psi s\}
$$


Where $\psi(s)$ are the convex search costs of the job. The optimal level of search by First order condition solves:

Equation 38

So following applies (we can get derivatives for):

$$
\psi\left(s^{*}\right)=\beta[U(w)-V(b, w)] ; V(b, w)=\frac{b+\beta s^{*} U(w)-\psi\left(s^{*}\right)}{1-\beta+\beta s}
$$

Equation 39

$$
U_{w}=\frac{1}{1+\beta} ; V_{w}=\frac{\beta s^{*}}{1-\beta+\beta s^{*}} \cdot \frac{1}{1+\beta} ; V_{s}=\frac{1}{1-\beta+\beta s^{*}}
$$

So, $\psi^{\prime \prime}\left(s^{*}\right)=\frac{\partial s^{*}}{\partial b}=-\beta V_{b} ; \psi^{\prime \prime}\left(s^{*}\right)>0 \quad$ and $\quad \psi^{\prime \prime}\left(s^{*}\right)=\frac{\partial s^{*}}{\partial w}=-\beta\left(U_{w}-V_{w}\right)$. And since $\psi^{\prime \prime}\left(s^{*}\right)>0 s^{*}$ decreases with $b$ and increases with $w$.

\section{One peculiar source of unemployment: social customs and a notion fair wage}

Here we are recalling Akerlof's (1980), Theory of social custom, of which unemployment may be a consequence, and a gift exchange model Akerlof's (1982), Labor Contracts as Partial Gift Exchange. Here code of behaviour $=\frac{\bar{\omega}}{\bar{\omega}+1}$, where $\bar{\omega}$ is a fair wage. Utility function of a worker is $: U=a_{L}+b_{L} K+c_{L} \epsilon R-d^{R} d^{C} \bar{C}$ where $a_{L} \in(-\infty, \infty) ; b_{L} \in(0, \infty) ; c_{L} \in$ $(0, \infty)$.Utility function of a capitalist is $U=a_{K}+b_{k} K+c_{k} R$ where $a_{K} \in(-\infty, \infty) ; b_{K} \in$ $(0, \infty) ; c_{K} \in(0, \infty)$.In the previous expressions: $d^{R}$ - e dummy variable 0 if worker obeys the code 1 if he disobeys, $d^{C}$ - is a dummy variable 0 if worker believes in the code of behavior and 1 otherwise, $R$ - is the worker reputation, $\bar{C}$-is a parameter that explains the loss in the utility of disobeying the code. $R=0$ means that the agent obeys the code, $R=-\mu \bar{R}$-agent disobeys the code ${ }^{*} \mu$ is a part of the population that believes the code, $\bar{R}$-Is a positive constant and $R=-d^{R} \mu \bar{R}$ while the evolution of the code of behavior is $\dot{\mu}=\beta(x-\mu)$. Where in the last expression $x$ is a part of population that conducts the code of behavior. Labor and capital are separated in three parts : $L_{1}, K_{1}$ is trade at $\bar{\omega}$ fair wage, $L_{2}, K_{2}$ is traded $\omega \neq \bar{\omega}, L_{3}, K_{3}$-is not trading at all. There exists threshold wage $\omega_{\text {crit }}$. If $\omega<\omega_{\text {crit }}$ capitalist will break the code and will pay $\omega \neq \bar{\omega}$ in exchange for unit of capital. If $\bar{\omega}>\omega_{\text {crit }}$, capitalist will trade unit of capital for $\bar{\omega}$.Hence critical wage is: $\omega_{c r i t}=\frac{a_{K}+\frac{b_{K}}{\bar{\omega}}}{a_{K}+\frac{b_{K}}{\bar{\omega}}-c_{K} \mu \bar{R}}$. If $\omega=\omega_{\text {crit }}$ then critical wage becomes: $\omega_{\text {crit }}=\frac{\bar{\omega}}{1+\left(\frac{c_{K}}{b_{K}}\right) \mu \bar{R} \bar{\omega}}$

In equilibrium (notional demand ND) :

- $L_{1}^{N D}=0 ; \omega<\omega_{\text {crit }}$

- $\bar{\omega} L_{1}^{N D}+\omega L_{2}^{N D}=K ; \omega=\omega_{\text {crit }} ; L_{1}^{N D} \geq 0 ; L_{2}^{N D} \geq 0$

- $L_{1}^{N D}=K / \bar{\omega} ; \omega>\omega_{\text {crit }}$

- $L_{2}^{N D}=\frac{K}{\omega} ; \omega<\omega_{\text {crit }}$

- $L_{2}^{N D}=0 ; \omega>\omega_{\text {crit }}$

Worker trades at rate $\bar{\omega}$ or $\omega$ dependent on : $a_{L}+b_{L} \bar{\omega} \gtrless a_{L}+b_{L} \omega-c_{L} \mu \epsilon \bar{R}-d^{C} \bar{C}$. According to previous inequality worker with tastes $\epsilon>\left(b_{L}(\omega-\bar{\omega})-d^{C} \bar{C} / c_{L} \mu \bar{R}\right.$ has Notional supply of labor traded at $\bar{\omega}$ per unit. Worker with $\epsilon<\left(b_{L}(\omega-\bar{\omega})-d^{C} \bar{C} / c_{L} \mu \bar{R}\right.$ has a equilibrium supply of labor traded at $\omega \neq \bar{\omega}$ per unit ff we take into consideration the distribution of tastes $F$ we got : $L_{1}^{N S}=L\left\{\mu\left(1-F\left(z_{l}\right)+(1-\mu)\left(1-F\left(z^{\prime}\right)\right\}\right.\right.$. If $\omega<\omega_{\text {crit }}$ $L_{1}^{N D}=0$.If $\omega>\omega_{\text {crit }}$ capitalist like to trade at $\bar{\omega}$, hence $L_{1}^{N D}=K / \bar{\omega}$,if $\omega<\bar{\omega}$ all workers will trade labor for capital $\bar{\omega}$, hence $L_{1}^{N S}=L$. Hence $L_{2}^{N S}=L\left\{\mu F\left(z_{l}\right)+(1-\mu)\left(1-F\left(z^{\prime}{ }_{l}\right)\right\}\right.$ and $L_{3}^{N S}=0$, where $z_{l}=\left(b_{L}(\omega-\bar{\omega})-\bar{C}\right) / c_{L} \mu \bar{R}$ and $z_{l}^{\prime}=b_{L}(\omega-\bar{\omega})-\bar{C} / c_{L} \mu \bar{R} . F(z)$ is a 
proportion of population with taste for labor/capital $\epsilon \leq z$, whereas $\epsilon$-are personal tastes. Equations for notional demand will become effective demand equations $: L_{2}^{E D}=\frac{K}{\omega} ; \omega<\omega_{\text {crit }}$ and $\bar{\omega} L_{1}^{E D}+\omega L_{2}^{E D}=K ; \omega=\omega_{\text {crit }} ; L_{1}^{E D} \geq 0 ; L_{2}^{E D} \geq 0 ;$ and $L_{2}^{E D}=0 ; \omega>\omega_{\text {crit }}$. Effective labor supply is traded at $\omega \neq \bar{\omega}, L_{2}^{E S}$ is the sum of the two expressions. First if $\omega>\bar{\omega}$ there are some workers that will trade $\omega$. If $\omega<\bar{\omega}$ there will be workers trying to find job at $\bar{\omega}$ but unsuccessfully. These workers decide whether will trade at a $\omega \neq \bar{\omega}$ and lose their reputation or not trade at all. Worker that is offering its labor at $\bar{\omega}$ has a probability of being successful $L_{1}^{E D} / L_{2}^{N S}$ and probability of being refused $1-\frac{L_{1}^{E D}}{L_{2}^{N S}}$. Utility of a worker that does not work is $a_{L}$. All workers with tastes between $\left(b_{L}(\omega-\bar{\omega})-d^{C} \bar{C} / c_{L} \mu \bar{R}\right.$ и $\left(b_{L} \omega-d^{C} \bar{C} / c_{L} \mu \bar{R}\right.$, will have probability $1-\frac{L_{1}^{E D}}{L_{2}^{N S}}$, of being unable to trade labor at rate $\bar{\omega}$ and they will trade at $\omega$ Asa result of which :

\section{Equation 40}

$$
L_{2}^{E S}(\omega)=L\left(1-\frac{L_{1}^{E D}}{L_{2}^{N S}}\right)\left\{\left\{\mu F\left(z_{u}\right)-F\left(z_{l}\right)\right\}+(1-\mu)\left[F\left(z_{u}^{\prime}\right)-F\left(z_{l}^{\prime}\right)\right]\right\}+L_{2}^{N S}(\omega)
$$

Where $: z_{u}=\frac{b_{L} \omega-\bar{C}}{c_{L} \mu \bar{R}} ; z_{l}=\frac{b_{L}(\omega-\bar{\omega})-\bar{C}}{c_{L} \mu \bar{R}} ; z_{u}^{\prime}=\frac{b_{L} \omega}{c_{L} \mu \bar{R}} ; z_{l}^{\prime}=\frac{b_{L}(\omega-\bar{\omega})}{c_{L} \mu \bar{R}}$. Value at which $L_{2}^{E S}=L_{2}^{E D}$ if $\omega=\omega_{\text {crit }}$, that value is : $L_{1}^{E D}=\left(K-\omega_{\text {crit }} L_{2}^{E D}\right) / \bar{\omega}$ and hence $L_{2}^{E S}\left(\omega_{\text {crit }}\right)=L\{1-$ $\left.\left(K-\omega_{\text {crit }} L_{2}^{E D}\right) / \bar{\omega} L_{1}^{N S}\right\}\left\{\mu F\left(z_{u}\right)+(1-\mu) F\left(z^{\prime}(u)\right\}^{1}\right.$. About the effective demand : $L_{2}^{E D}=$ $\frac{K}{\omega_{\text {crit }}}=0$. If there is equilibrium it is $\in\left(0, \frac{K}{\omega_{\text {crit }}}\right)$, which is a short run equilibrium for $\omega$.

Proposition: There is no equilibrium if $\omega>\omega^{*}$

Proof: Let $\omega>\omega^{*}$, than $L_{2}^{E S} \neq L_{2}^{E D}$ for $\omega>\omega^{*}$

$\frac{L_{2}^{E S}}{L}=\left(1-\frac{L_{1}^{E S}}{L}\right)$ за $\omega>\omega^{*} ; \frac{L_{2}^{E D}}{L}=\left(1-\frac{L_{1}^{E S}}{L_{1}^{N D}}\right) K / L_{\omega} \omega$ for $\omega^{*} \leq \omega \leq \max \left(\frac{b_{K}}{c_{K} \mu \bar{R}, \omega^{*}}\right)$

$\frac{L_{2}^{E D}}{L} \leq \frac{\left(1-\frac{L_{1}^{E S}}{L_{1}^{N D}}\right) K}{L_{\omega}}=\left(1-\frac{\frac{L_{1}^{E S}}{K}}{\bar{\omega}}\right)$ because $L_{1}^{N D}=K / \bar{\omega} ; \omega>\omega_{\text {crit }}$

$\frac{L_{2}^{E D}}{L} \leq \frac{\left(1-\frac{L_{1}^{E S}}{L_{1}^{N D}}\right) K}{L_{\omega}}=\left(1-\frac{\frac{L_{1}^{E S}}{K}}{\bar{\omega}}\right)=\left(\frac{1}{\omega}-\frac{L_{1}^{E S}}{L \frac{\bar{\omega}}{\omega}}\right)$ because $\frac{K}{L}=1$

$\frac{L_{2}^{E D}}{L} \leq \frac{\left(1-\frac{L_{1}^{E S}}{L_{1}^{N D}}\right) K}{L_{\omega}}=\left(1-\frac{\frac{L_{1}^{E S}}{K}}{\bar{\omega}}\right)=\left(\frac{1}{\omega}-\frac{L_{1}^{E S}}{L \frac{\bar{\omega}}{\omega}}\right) \leq\left(\frac{1}{\omega}-\frac{L_{1}^{E S}}{L}\right)$ because $\bar{\omega}<1 ;$ if $L_{1}^{E S} \neq 0$

$\frac{L_{2}^{E D}}{L} \leq \frac{\left(1-\frac{L_{1}^{E S}}{L_{1}^{N D}}\right) K}{L_{\omega}}=\left(1-\frac{\frac{L_{1}^{E S}}{K}}{\bar{\omega}}\right)=\left(\frac{1}{\omega}-\frac{L_{1}^{E S}}{L \frac{\bar{\omega}}{\omega}}\right) \leq\left(\frac{1}{\omega}-\frac{L_{1}^{E S}}{L}\right) \leq 1-\frac{L_{1}^{E S}}{L}$ because $\omega>\omega^{*}<\bar{\omega}>1$

With less strict inequality $L_{1}^{E S}=0$.

$\frac{L_{2}^{E D}}{L}<\left(1-\frac{E_{1}^{E S}}{L}\right)=\frac{L_{2}^{E S}}{L}$ hence $L_{2}^{E D} \neq L_{2}^{E S}$ за $\omega>\omega^{*}$

Proposition 1: On a long run $\mu=\left(L_{1}+L_{3} /\right) L$ representing the individuals that are obeying the code. In a short run $\frac{K}{\omega}=L \quad \omega=\frac{K}{L}=1$.According to a classical economics there is one equilibrium $\mu=0 ; \frac{L_{2}^{E D}}{L}=\frac{L_{2}^{E S}}{L}=\omega=1$.

\footnotetext{
${ }^{1}$ Where $z_{u}=\left(b_{L} \omega_{\text {crit }}-\bar{C}\right) / c_{L} \mu \bar{R} ; z_{u}^{\prime}=\left(b_{L} \omega_{\text {crit }}-\bar{C}\right) / c_{L} \mu \bar{R} ; F\left(z_{l}\right)=F\left(z_{l}^{\prime}\right)=0$
} 
Proof: If $\omega=\frac{K}{L}=1 ; \mu=0$ then $\omega<\omega_{\text {crit }}=\bar{\omega} ; L_{2}^{E D}=K / \omega$ for $\omega<\omega_{\text {crit }}$ and $\frac{L_{2}^{E S}}{L}=$ $\left\{\frac{L-0}{L}\right\}\left\{\mu F\left(Z_{u}\right)+(1-\mu) F\left(z_{u}^{\prime}\right)\right\}$ where distribution of tastes is $F\left(z_{u}\right)=\frac{1}{\epsilon_{1}-\epsilon_{0}}\left[\min \left(z, \epsilon_{1}\right)-\right.$ $\left.\min \left(z, \epsilon_{0}\right)\right]$ where $z_{u}=\left(b_{L} \omega-\bar{C}\right) / c_{L} \mu \bar{R}$ and $z_{u}^{\prime}=b_{L} \omega / c_{L} \mu \bar{R}$ with $\frac{L_{2}^{E S}}{L}=1$ which is translated into : $L_{2}^{E S}=L_{2}^{E D}=L, \frac{L_{1}^{E S}+L_{2}^{E D}}{L}=\mu=0$ for $\omega=1$ hence $\frac{L_{2}^{E S}}{L}=\frac{L_{2}^{E D}}{L}=\omega=1, \mu=$ 0 is a long run equilibrium $\mathbf{m}$

Proposition 2: Ако $\bar{C}<b_{L} ; \frac{L_{2}^{E S}}{L}=\frac{L_{2}^{E D}}{L}=\omega=1$ is the only short run equilibrium as $\bar{R} \rightarrow 0$. If $\bar{C}<b_{L}$, and $0 \leq \mu \leq 1-1 / \min \left(\frac{\bar{C}}{b_{L}}, \bar{\omega}\right)$ is a long run equilibrium with $\omega=\frac{1}{1-\mu}$ и $\frac{L_{2}^{E S}}{L}=$ $1-\mu$ as $\bar{R} \rightarrow 0$.

Proof: $\lim _{\bar{R} \rightarrow 0} \omega_{\text {crit }}=0$ there exists only one equilibrium for $\omega<\omega_{\text {crit }}$ if $\omega<$ $\bar{\omega}, \omega<\lim _{\bar{R} \rightarrow 0} \omega_{\text {crit }}=0$ and $\frac{L_{2}^{E S}}{L}=\mu F\left(Z_{u}\right)+(1-\mu) F\left(z_{u}^{\prime}\right)$ also $\frac{L_{2}^{E S}}{L}=1$ if $\omega>\frac{\bar{C}}{b_{L}}$. If $\omega=$ $1, \omega<\omega_{\text {crit }}=\lim _{R \rightarrow 0} \omega_{\text {crit }}$ and with assumption that $\bar{\omega}>1$, so for $\omega=1$, if $\frac{\bar{c}}{b_{L}}<1$, we have $\frac{L_{2}^{E S}}{L}=\frac{L_{2}^{E D}}{L}=\frac{K}{\omega L}=1 \cdot \frac{L_{2}^{E S}}{L}=\frac{L_{2}^{E D}}{L}=\omega=1$ is the only short run equilibrium for $\omega<\omega_{\text {crit }}$. If $\omega<1$ then $\frac{L_{2}^{E S}}{L}<1$ but $\frac{L_{2}^{E D}}{L}>1$ therefore $\mathrm{L}_{2}^{\mathrm{ES}} \neq \mathrm{L}_{2}^{\mathrm{ED}} \mathbf{m}$.

Proposition 3: $\omega_{\text {crit }} \neq \omega$ for $\lim \overline{\mathrm{R}} \rightarrow 0$

Proof: If $\omega_{\text {crit }}<\bar{\omega}$ then $\mathrm{L}_{2}^{\mathrm{ES}}=\mathrm{L}_{2}^{\mathrm{ED}}$ because $\frac{\mathrm{L}_{2}^{\mathrm{ES}}}{\mathrm{L}}=\left\{1-\left(\mathrm{K}-\omega_{\text {crit }} \mathrm{L}_{2}^{\mathrm{ES}}\right) / \bar{\omega} \mathrm{L}\right\}\left\{\mu \mathrm{F}\left(\mathrm{z}_{\mathrm{u}}\right)+\right.$ $(1-\mu) \mathrm{F}\left(\mathrm{z}^{\prime}(\mathrm{u})\right\}$ where $\mathrm{F}\left(\mathrm{z}_{\mathrm{u}}\right)$ is given as $: \mathrm{z}_{\mathrm{u}}=\left(\mathrm{b}_{\mathrm{L}} \omega_{\text {crit }}-\overline{\mathrm{C}}\right) / \mathrm{c}_{\mathrm{L}} \mu \overline{\mathrm{R}} ; \mathrm{cz}_{\mathrm{u}}^{\prime}=\mathrm{b}_{\mathrm{L}} \omega_{\text {crit }} / \mathrm{c}_{\mathrm{L}} \mu \overline{\mathrm{R}}$ and $\frac{L_{2}^{E S}}{L}=\frac{1-\frac{K}{L \bar{\omega}}}{1-\frac{\omega_{\text {crit }}}{\omega}}$. Because $\omega_{\text {crit }}<\bar{\omega}$ for $\bar{R}>0$ and since $\lim _{\mathrm{R} \rightarrow 0} \omega_{\text {crit }}=\bar{\omega}$ it follows $\lim _{\mathrm{R} \rightarrow 0} \frac{\mathrm{L}_{2}^{\mathrm{ES}}}{\mathrm{L}}>$ $\frac{\mathrm{K}}{\mathrm{L} \omega_{\text {crit }}}$ and $\lim _{\mathrm{R} \rightarrow 0} \mathrm{~L}_{2}^{\mathrm{ED}} \neq \mathrm{L}_{2}^{\mathrm{ES}}$ for $\omega=\omega_{\text {crit }}$, this opposes the assumption that $\mathrm{L}_{2}^{\mathrm{ED}}=\mathrm{L}_{2}^{\mathrm{ES}}$ hence $\omega=\omega_{\text {crit }}$ is not equilibrium value for $\omega \mathbf{m}$.

Proposition 3. There is no equilibrium for $\omega>\omega_{\text {crit }}$ for $\lim \bar{R} \rightarrow 0$. Since we know that : $\frac{\mathrm{L}_{2}^{\mathrm{ES}}}{\mathrm{L}}=\left(1-\left(\frac{\mathrm{K}}{\mathrm{L} \bar{\omega}}\right) / \bar{\omega} \mathrm{L}\right)\left\{\mu \mathrm{F}\left(\mathrm{z}_{\mathrm{u}}\right)-\mathrm{F}\left(\mathrm{z}_{\mathrm{l}}\right)+(1-\mu) \mathrm{F}\left(\mathrm{z}^{\prime}(\mathrm{u})-\mathrm{F}\left(\mathrm{z}^{\prime}(\mathrm{l})\right\}+\mu \mathrm{F}\left(\mathrm{z}_{\mathrm{l}}\right)+(1-\right.\right.$ $\mu) \mathrm{F}\left(\mathrm{z}_{1}^{\prime}\right)$ where $\mathrm{z}_{\mathrm{l}}=\left(\mathrm{b}_{\mathrm{L}}(\omega-\bar{\omega})-\overline{\mathrm{C}}\right) / \mathrm{c}_{\mathrm{L}} \mu \overline{\mathrm{R}}$ and $\mathrm{z}_{1}^{\prime}=\mathrm{b}_{\mathrm{L}}(\omega-\bar{\omega}) / \mathrm{c}_{\mathrm{L}} \mu \overline{\mathrm{R}}$. If we evaluate $\lim \bar{R} \rightarrow 0$ за $\frac{\bar{C}}{b_{L}}<1$ will see that, $\frac{L_{2}^{E S}}{L} \geq 1-\frac{K}{L \bar{\omega}}>0$ for $\omega>\omega_{\text {crit }}$ and $L_{2}^{E D}=0$ за $\omega>\omega_{\text {crit }}$ So that $L_{2}^{E D} \neq L_{2}^{E S}$ за $\omega>\omega_{\text {crit }}$

Only equilibrium occurs when $\lim \overline{\mathrm{R}} \rightarrow 0$, and the equilibrium is short-run $\frac{\mathrm{L}_{2}^{\mathrm{ES}}}{\mathrm{L}}=\frac{\mathrm{L}_{2}^{\mathrm{ED}}}{\mathrm{L}}=\omega=$ 1 with $\overline{\mathrm{C}}<\mathrm{b}_{\mathrm{L}}$

Proposition 4: if $\bar{C}>b_{L}$, any $\mu$ where $0 \leq \mu \leq 1-\frac{1}{\min \left(\frac{\bar{C}}{b_{L}}, \omega\right)}$ is a long run equilibrium if $\omega=$ $\frac{1}{1-\mu}$ and $\frac{\mathrm{L}_{2}^{E S}}{L}=1-$ as $\bar{R} \rightarrow 0$.

Proof: From previously we know that $\frac{\mathrm{L}_{2}^{\mathrm{ES}}}{\mathrm{L}}=1-\mu$ if $\omega<\frac{\overline{\mathrm{C}}}{\mathrm{b}_{\mathrm{L}}}$, as before $\omega=\frac{1}{1-\mu}<\omega_{\text {crit }}$, so $\frac{L_{2}^{E D}}{L}=(1-\mu) \frac{K}{L}=1-\mu$.So, $0 \leq \frac{1}{1-\mu} \leq \min \left(\frac{\bar{C}}{b_{L}}, \omega\right) ; \frac{L_{2}^{E S}}{L}=\frac{L_{2}^{E D}}{L}$ such as $\omega=\frac{1}{1-\mu}$ gives short run equilibrium as $\bar{R} \rightarrow 0$.Furthermore $\frac{L_{2}^{E S}}{L}=\frac{L_{2}^{E D}}{L}=1-\mu$ is a long run equilibrium because: $\dot{\mu}=\beta(1-(1-\mu)-\mu)=0 \mathbf{a}$.

Proposition 5: for $\bar{R}$ large enough, there exist stable equilibrium $\mathrm{L}_{2}^{E S}=L_{2}^{E D}=0$ and $\mu=1$ 
Proof: for $\quad \bar{\omega}>\omega>\omega_{\text {crit }} \quad$ we know that $\frac{L_{2}^{E S}}{L}=\left(1-\left(\frac{K}{L \bar{\omega}}\right)\right)\left\{\mu F\left(z_{u}\right)-F\left(z_{l}\right)+\right.$ $(1-\mu) F\left(z^{\prime}(u)\right\}$

And let $\bar{R}>b_{L} \bar{\omega} / c_{L} \epsilon_{0}$. Than $\bar{\omega}>\omega>\bar{\omega} /\left(1+\left(\frac{c_{K}}{b_{K}}\right) \bar{R} \bar{\omega}\right.$ with $\mu \rightarrow 1$.Then: $\frac{L_{2}^{E S}}{L}=0 ; \mu=$ 1 and $\frac{L_{2}^{E S}}{L}=\frac{L_{2}^{E D}}{L}=0 \Rightarrow 1-\mu=1-1=0$.Since $\frac{\left(L_{1}+L_{3}\right)}{L_{1}}=1$. Near $1 \mu<1, \mu=1$ motion is given as: $\dot{\mu}=\beta\left(\frac{L_{1}+L_{3}}{L-\mu}\right)=\beta(1-\mu)>0$ so $\mu=1$ is a stable equilibrium $\mathbf{m}$.

In the fair wage model Akerlof (1982) explains that there exists fair wage as a function of : $w_{i, t+1}^{f}=f\left(w_{i, t}, w_{0}, b_{u}, u, e_{i}, e_{0}\right)$. Where: $w_{i, t+1}^{f}$-is the perceived wage of $i$ at $t+1 ; w_{i, t}$-is the actual wage paid at $t ; w_{0}$-is the wage paid to others in i's reference set; $b_{u}$-is the unemployment benefits of the individuals reference set in the current and previous periods; $u$ - is the number of unemployed in the reference set in the current and previous periods; $e_{i}$-is the individualís work rules in current and previous periods; $e_{0}$ - is the work rules of people in the individualís reference set in current and previous periods.Norms equation here is given as follows next : $e_{n}=$ $e_{n}\left(\{w(e, \epsilon)\}, e_{\min }, u_{i}, \ldots, u_{J} ; w_{0}, u, b_{u}\right)$, where $\{w(e, \epsilon)\}$-is the function that relates wages of a worker of type $\epsilon$ to his effort (thus, this is the firm's remuneration system).Here $e_{\text {min }}$-work rule $; u_{J}$-is the utility of $\mathrm{j}^{\text {th }}$ worker $; w_{0}$-is the wage paid by the other firms $; u$-unemployment rate and $b_{u}$-unemployment benefit. Worker takes a job if: $\max _{\left(e \geq e_{\min }\right)} u\left(e_{n}, e, w, \epsilon\right)>u\left(b_{u}, \epsilon\right)$. For the firms Output is: $q=f\left(e_{1}, e_{2}, \ldots, e_{J}\right)$. Where $J$ is the number of workers hired. The firm chooses wage function $w(e, \epsilon)$, work rules $e_{\min }$ and number of workers to maximize:p $f\left(e_{1}, \ldots, e_{J}\right)-$ $\sum_{j=1}^{J} w(e, \epsilon)$. Where $p$ is the output price. It is assumed that workers of type $\epsilon$ are offered jobs at random. Model here explains equilibrium unemployment. Let $\bar{l}$ be the workers per firm be the supply of labor. That is, this is the number of workers divided by the number of firms.Let output be: $q(e, n)=e n^{a}$. There is no worker heterogeneity, and all workers will exert effort equal to the norm: $e=e_{n}$. Let the effort norm be a function of the firm's wage relative to the reference wage: $e_{n}=-a+b\left(\frac{w}{w_{r}}\right)^{\gamma}, \gamma<1$. Let the reference wage be the geometric mean of the outside wage and the unemployment benefit so that: $w_{r}=w_{0}^{1-u} b_{u}^{u}$. Where $u$ is the unemployment rate, $w_{0}$ is the wage paid by other firms, and $b_{u}$ is the unemployment benefit. So $: e_{n}=-a+b\left(\frac{w}{w_{0}^{1-u} b_{u}^{u}}\right)^{\gamma}, \gamma<1$ That is, it has the typical employment and wage levels. Let's suppose that $u=u_{0}>0$, the paper asserts that the firm can obtain all the workers it wants at any wage. Firms now maximize: $\max _{n, w} \Pi=(e n)^{\alpha}-w n \quad$ s.t. $e=e_{n}$ where $e_{n}=-a+$ $b\left(\frac{w}{w_{r}}\right)^{\gamma}$ and reservation wage $w_{r}=w_{0}^{1-u} b_{u}^{u}$.first derivative of profit with respect to employment gives: $\frac{\partial \Pi}{\partial n}=0=\alpha e^{\alpha} n^{\alpha-1}-w$,frm there $\alpha e^{\alpha} n^{\alpha-1}=w$ and $n^{\alpha-1}=\alpha^{-1} w e^{-\alpha}$ and labor $n=\left[\frac{w}{\alpha e^{\alpha}}\right]^{\frac{1}{\alpha-1}}$ with optimal demand for labor given as: $n^{*}=\left[\frac{w}{\alpha\left[-a+b\left(\frac{w}{w_{r}}\right)^{\gamma}\right]^{\alpha}}\right]^{\frac{1}{\alpha-1}}$.Now the Solow condition (Solow (1979)) is the observation that if effort depends on the wage, then at the optimal wage level, the elasticity of effort with respect to the wage must be one (otherwise, the wage is too high or too low). Solow condition states that:

Equation 41

$e_{n}=-a+b\left(\frac{w}{w_{r}}\right)^{\gamma}$ and $\frac{\partial e}{\partial w}=\gamma b\left(\frac{w}{w_{r}}\right)^{\gamma-1} ; w_{r}^{-1}=\gamma b w^{\gamma-1} w_{r}^{-\gamma}$ 
Where $: \frac{\partial e}{\partial w} \times \frac{w}{e}=1=\frac{w \gamma b w^{\gamma-1} w_{r}^{-\gamma}}{-a+b\left(\frac{w}{w_{r}}\right)^{\gamma}}$ and $-a+b\left(\frac{w}{w_{r}}\right)^{\gamma}=w \gamma b w^{\gamma-1} w_{r}^{-\gamma}$ where $b(1-\gamma) w^{\gamma} w_{r}^{-\gamma}=a$ also $w^{\gamma} w_{r}^{-\gamma}=\frac{a}{(b(1-\gamma))}$ with $w^{\gamma} w^{(u-1) \gamma} b_{u}^{-\gamma u}=\frac{a}{(b(1-\gamma))}$ and $w^{u \gamma}=$ $b_{u}^{\gamma u} \frac{a}{(b(1-\gamma))}$ and the wage here is given as: $w=b_{u}\left[\frac{a}{(b(1-\gamma))}\right]^{\frac{1}{u \gamma}}$. We can see that $\frac{\partial w}{\partial u}<0$ thus the Solow condition is failing in the unemployment rate. But we notice that $w>w_{r}$, under the following condition $: b_{u}\left[\frac{a}{(b(1-\gamma))}\right]^{\frac{1}{u \gamma}}>\left[b_{u}\left[\frac{a}{(b(1-\gamma))}\right]^{\frac{1}{u \gamma}}\right]^{1-u} \quad b_{u}^{u}$ or $b_{u}\left[\frac{a}{(b(1-\gamma))}\right]^{\frac{1}{u \gamma}}>$ $b_{u}\left[\frac{a}{(b(1-\gamma))}\right]^{\frac{1-u}{u \gamma}}$ and $\left[\frac{a}{(b(1-\gamma))}\right]>\left[\frac{a}{(b(1-\gamma))}\right]^{1-u}$ so that means $1>\left[\frac{a}{(b(1-\gamma))}\right]^{-u}$. Which means that the Solow wage is greater than the reference wage if $f$ the elasticity of the effort with respect to the wage is initially greater than 1 , meaning that the increase in wage beyond the reference wage pay for themselves. Now in the demand for labor equation we can plug the previous in the maximization: $n^{*}=\left[\alpha^{-1} w\left(-a+b\left(\frac{w}{w_{r}}\right)^{\gamma}\right)^{1-\alpha}\right]^{\frac{1}{\alpha-1}}$ and after some manipulation we get : $n^{*}==\left[\alpha^{-1} b_{U}\left(\frac{\alpha \gamma}{1-\gamma}\right)^{1-\alpha}\left(\frac{\alpha}{b(1-\gamma)}\right)^{\frac{1}{\gamma u}}\right]^{\frac{1}{\alpha-1}}$. If this demand function is consistent with the unemployment rate, then the supply of labor must be:

\section{Equation 42}

$$
\bar{l}=l_{0}=\frac{n^{*}}{1-u}=(1-u)^{-1}\left[\alpha^{-1} b_{U}\left(\frac{\alpha \gamma}{1-\gamma}\right)^{1-\alpha}\left(\frac{\alpha}{b(1-\gamma)}\right)^{\frac{1}{\gamma u}}\right]^{\frac{1}{\alpha-1}}
$$

Since the reference wage us failing here with the unemployment rate, and henceforth is also rising in the unemployment rate, wages will fal and labor demand will rise with the increase in unemployment. We can see that $: \frac{\partial \ln n}{\partial u}=\frac{1}{\alpha-1 \gamma u^{2}} \ln \left(\frac{\alpha}{b(1-\gamma)}\right)$ or $\frac{\partial \ln n}{\partial u}=$ $\frac{1}{\alpha-1 \gamma u^{2}} \ln \left(\frac{\alpha}{b(1-\gamma)}\right)>0$ if $\frac{\alpha}{b(1-\gamma)}>1 ; \alpha<1$. But notice that if $b=0$, then effort is increasing in wage, If $\alpha<0$.then $e=-\alpha>0$,so effort is positive at any wage. In this case firm will choose labor:

\section{Equation 43}

$$
w=\alpha((-\alpha) n)^{\alpha-1} ; \alpha^{-1} w(-\alpha)^{1-\alpha}=n^{\alpha-1} ; n=\left[\alpha^{-1} w(-\alpha)^{1-\alpha}\right]^{\frac{1}{\alpha-1}}
$$

And of course, the wage is equal to the marginal product of labor. So, we should expect that labor markets will clear (that is, all workers who want work at wage $w$ will receive it- though of course, if many additional workers wanted work, this would lower the wage, but that's still market clearing). The first point is that if worker effort depends on a reference wage, then it may be logical for firms to pay a wage above that level to obtain extra effort. If so, the profit maximizing choice of labor input will not equate the marginal product with the reservation wage but rather with Solow wage (i.e the efficiency wage). At this point there will be equilibrium unemployment, that is workers will be willing to work at rate $w$ but firms will have no incentives to hire them. Because marginal product of labor at $n^{*}$ is equated with the efficiency wage (Solow wage). 


\section{Fair pricing of Eyster, Madarsz, Michaillat, ( 2019) in Monopoly model and New Keynesian setting}

Prices are not fully flexible nor they are fixed ,see Carlsson and Skans (2012); De Loecker et al. (2016); Caselli, Chatterjee, Woodland (2017); Ganapati, Shapiro, and Walker 2019, Eyster, Madarsz, Michaillat,( 2019).This price rigidity is of first order importance since it determines the transmission of shocks and government policies to the economy. Rotemberg (2005) developed the first theory of price rigidity based on fairness considerations, also see Rotemberg (2011). Yet the theories of price rigidity do not include fairness yet theories of price rigidity almost never includ fairnessconsiderations (Blanchard 1990; Mankiw and Reis 2010). These models of fair pricing are explained in , Eyster, Madarsz, Michaillat,( 2019).In the monopoly case: the markup charged by the monopoly is lower and is of size $M^{p}(p)=\frac{P}{\mathcal{C}^{p}(p)}$, where $\mathcal{C}^{p}(p)$ is a given by a belief function. The perceived markup determines the fairness of the transaction through a fairness function $F\left(M^{p}\right)>0$. Both functions $\mathcal{C}^{p}(P)$ and $F\left(M^{p}\right)$ are assumed to be twice differentiable.Customer consumption is given as: $Z=F(M p(P)) \cdot Y$, where a quantity $Y$ of the good is purchased at price $P$. Customer faces budget constraint: $P \cdot Y+B=$ $W$; where $W>0$ designates initial wealth, and $B$ designates remaining money balances. Fairness- adjusted consumption and money balances enter a quasilinear utility function $: \frac{\epsilon}{\epsilon-1}$. $z^{\frac{\epsilon-1}{\epsilon}}+B$. Where the parameter $\epsilon>1$ governs the concavity of the utility function. Given fairness factor $F$ and price $P$, the customer chooses purchases $Y$ and money balances $B$ to maximize utility subject to the budget constraint. The monopoly has constant marginal cost $C$ $>0$. It chooses price $P$ and output $Y$ to maximize prots $(P-C) \cdot Y$ subject to customers' demand for its good.The demand curve is given as: $Y^{d}(P)=P^{-\epsilon} \cdot F(M p(P))^{\epsilon-1}$. The price elasticity of demand, normalized to be positive: $E=\frac{d \ln \left(Y^{d}\right)}{d \ln (P)}=\frac{P}{-Y^{d}} \cdot \frac{d Y^{d}}{d P}$. The first-order condition then yields the classical result that: $P-\frac{E}{E-1} \cdot C$, that is, the monopoly optimally sets its price at a markup $M=\frac{E}{E-1}$ over marginal cost. To learn more about the monopoly's markup, we compute the elasticity $E$. Now, we find $E=\epsilon+(\epsilon-1) \cdot \phi \cdot\left[1-\frac{d \ln \left(\mathcal{C}^{P}\right)}{d \ln (P)}\right]$.

Lemma 1 When customers care about fairness, the elasticity of the fairness function

Equation 44

$$
\phi(M p)=-\frac{d \ln (F)}{d \ln (M p)}
$$

is strictly positive and strictly increasing on $\left(0, M^{h}\right)$ with $\lim _{M p \rightarrow 0} \phi\left(M^{P}\right)=0$ and $\lim _{M p \rightarrow M^{h}} \phi\left(M^{P}\right)=+\infty$, As an implication, the superelasticity of the fairness function:

\section{Equation 45}

$$
\sigma=\frac{d \ln (\phi)}{d \ln (M p)}
$$

Proof. By definition, $\phi(M p)=-M p \cdot F^{\prime}\left(M^{p}\right) / F(M p)$. Using the properties of the fairness function listed in definition, $F\left(M^{p}\right)>0$ and $F^{\prime}\left(M^{p}\right)<0$, so $\phi(M p)>0$. The properties also indicate that $F>0$ is decreasing in $M_{p}$, and that $F_{0}<0$ is decreasing in $M_{p}$ (as $F$ is concave in $M p$ ). Thus, both $1 / F>0$ and $-F^{\prime}>0$ are increasing in $M^{p}$, which implies that $\phi$ is strictly increasing in $M^{p}$. The properties also indicate that $F(0)>0$ and $F^{\prime}(0)$ is finite, so $\lim _{M p \rightarrow 0} \phi\left(M^{P}\right)=0$. Last, the properties indicate that $F\left(M^{h}\right)=0$ while $M^{h}>0$ and $F^{\prime}\left(M^{h}\right)<0$, so that 
$\lim _{M p \rightarrow M^{h}} \phi\left(M^{P}\right)=+\infty$. The final result immediately follows, as $\sigma=M^{p} \cdot \phi^{\prime}\left(M^{p}\right) /$ $\phi\left(M^{p}\right), \phi^{\prime}\left(M^{p}\right)>0$, and $\phi\left(M^{p}\right)>0 \mathbf{m}$.

In the New Keynesian model with fairness, the perceived price markup evolves according to $: \widehat{m^{p}}(t)=\gamma\left[\hat{\pi}(t)+\widehat{m^{p}}(t-1)\right.$. Accordingly, the perceived price markup is a discounted sum of lagged inflation terms: $\widehat{m^{p}}(t)=\sum_{s=0}^{\infty} \gamma^{s+1} \hat{\pi}(t-s)$. Because of its autoregressive structure, the perceived price markup is fully determined by past inflation. As a result, the short-run Phillips curve involves not only forward-looking elements - expected future inlation and employment - but also backward-looking elements - past inflation.In the New Keynesian model with fairness, the short-run Phillips curve is

Equation 46

$$
(1-\delta \gamma) \widehat{m^{p}}(t)-\lambda_{1} \hat{n}(t)=\delta \gamma \mathbb{E}_{t}(\hat{\pi}(t+1))-\lambda_{2} \mathbb{E}_{t}(\hat{n}(t+1))
$$

Where

\section{Equation 47}

$$
\begin{aligned}
& \lambda_{1} \equiv(1+\eta) \frac{\epsilon+(\epsilon-1) \gamma \bar{\phi}}{\gamma \bar{\phi} \bar{\sigma}}\left[1+\frac{(1-\delta) \gamma}{1-\delta \gamma} \bar{\phi}\right] \\
& \lambda_{2} \equiv(1+\eta) \delta \frac{\epsilon+(\epsilon-1) \gamma \bar{\phi}}{\bar{\phi} \bar{\sigma}}\left[1+\frac{(1-\delta) \gamma}{1-\delta \gamma} \bar{\phi}\right]
\end{aligned}
$$

Hence short run equilibrium Philips curve is hybrid, including both past and future inflation rates: $(1-\delta \gamma) \sum_{s=0}^{\infty} \gamma^{s+1} \hat{\pi}(t-s)-\lambda_{1} \hat{n}(t)=\delta \gamma \mathbb{E}_{t}(\hat{\pi}(t+1))-\lambda_{2} \mathbb{E}_{t}(\hat{n}(t+1))$.In the previous expression $\hat{n}(t)$ is the employment. About the technology shocks it is assumed that the logarithm of technology $A(t)$ in the production function $Y_{j}(t)=A_{j}(t) N_{j}(t)^{a}$ follows an $\mathrm{AR}(1)$ process, such that: $\hat{a}(t)=\mu^{a} \cdot \hat{a}(t-1)+\zeta^{a}(t)$ where the disturbance $\zeta^{a}(t)$ follows a white-noise process with mean zero, and $\mu^{a} \in(0 ; 1)$. Pricing theory here implies that monetary policy is nonneutral in the short run, so that a transitory monetary shock affects employment. Here we develop another implication of the theory:monetary policy is nonneutral in the long run, so that different rates of steady-state inflation lead to different levels of steadystate employment. In steady state the real interest rate equals the time discount rate $\rho \equiv$ $-\ln (\delta)$; therefore, by choosing $i_{0}$, monetary policy perfectly controls steady-state inflation: $\bar{\pi}=\frac{\rho-\bar{l}_{0}}{\psi-1}$. To obtain zero inflation, it suffices to set $\bar{l}_{0}=\rho$; to obtain higher inflation, it suffices to reduce $\overline{l_{0}}$. Kahneman, Knetsch, and Thaler (1986) have hypothesized that "any stable state of affairs tends to become accepted eventually". We adapt this idea to our model by assuming that people become partially acclimated to the steady-state inflation rate. Formally, we generalize the fairness function to: $F\left(M^{p}\right)=1-\theta \cdot\left(M^{p}-M^{f}\right)$, where $M^{f}$ is the fair markup resulting from acclimation. We assume that the fair markup is the weighted average of the standard markup, $\frac{\epsilon}{\epsilon-1}$, and the steady-state perceived markup $\overline{M^{p}}: M^{f}=\chi \cdot \overline{M^{p}}+(1-\chi)$. $\frac{\epsilon}{\epsilon-1}$. The parameter $\chi \in[0 ; 1]$ measures acclimation: when $\chi=0$, there is no acclimation, as in the previous version of the paper; when $\chi=1$, there is perfect acclimation, so people do not mind whatever is happening in steady state; when $\chi \in(0 ; 1)$, people may be permanently satisfied or dissatisfied in steady state, but less than when $\chi=0$. In the New Keynesian model with fairness, the steady-state perceived price markup is a strictly increasing function of steadystate inflation: 
Equation 48

$$
\overline{\mathrm{M}^{\mathrm{p}}}(\pi)=\frac{\epsilon}{\epsilon-1} \cdot \exp \left(\frac{\gamma}{1-\gamma} \bar{\pi}\right)
$$

Hence, the steady-state fairness factor is a weakly decreasing function of steady-state inflation:

Equation 49

$$
\overline{\mathrm{F}}(\bar{\pi})=1-\theta \cdot(1-\chi) \cdot\left[\overline{\mathrm{M}^{\mathrm{p}}}(\pi)-\frac{\epsilon}{\epsilon-1}\right]
$$

Accordingly, the steady-state elasticity of the fairness function is a strictly increasing function of steady-state inflation: $\bar{\phi}(\bar{\pi})=\frac{\theta \cdot \overline{\mathrm{M}^{\mathrm{p}}}(\bar{\pi})}{\overline{\mathrm{F}}(\bar{\pi})}$. In the New Keynesian model with fairness, the steady-state price markup is a strictly decreasing function of steady-state inflation:

Equation 50

$$
\overline{\mathrm{M}^{\mathrm{p}}}(\pi)=1+\frac{1}{\epsilon-1} \cdot \frac{1}{1+\frac{(1-\delta) \gamma}{1-\delta \gamma} \bar{\phi}(\bar{\pi})}
$$

Hence, steady-state employment is a strictly increasing function of steady-state inflation:

\section{Equation 51}

$$
N(t)=\left[\frac{(v-1) a}{v} \cdot \frac{1}{\bar{M}(\pi)}\right]^{\frac{1}{1+\eta}}
$$

Thus, the long-run Phillips curve is not vertical (fixed $\overline{\mathrm{N}}$ ) but upward sloping

\section{RBC and NK DSGE models with labor hours as proxy for labor supply}

In these models we will see how productivity or other shock are affecting labor supply. Standard business cycle model is very close to the canonical neo-classical growth model, this is extend the set-up with several real rigidities taken from Christiano et al. (2005) and Smets and Wouters (2003, 2007) which aim at enhancing the empirical relevance of macro-models.In this RBC model economy is populated by a large number of households $j \in[0,1]$, the utility function of a representative household is given as:

\section{Equation 52}

$$
u\left(c_{t}(j), h_{t}(j)\right)=\frac{c_{t}(j)^{1-\sigma^{c}}}{1-\sigma^{c}} \cdot \frac{h_{t}(j)^{1+\frac{1}{\sigma^{L}}}}{1+\frac{1}{\sigma^{L}}}
$$

Where $\sigma^{c}$ is the risk aversion, and $\sigma^{L}$ is the Frisch elasticity of labor supply ${ }^{1} . u($.$) represents$ the utility increasing from consumption $c_{t}(j)$, and decreasing from hours worked $h_{t}(j)$. Welfare is the sum fo current and expected utilities: $w_{t}(j)=\sum_{\tau=o}^{+\infty} \beta^{\tau} u\left(c_{t+\tau}(j), h_{t+\tau}(j)\right)$. Additionally, the production function follows a Cobb-Douglas technology:

\footnotetext{
${ }^{1}$ The Frisch elasticity measures the relative change of working hours to a one-percent increase in real wage, given the marginal utility of wealth $\lambda$.In the steady-state benchmark model is given as:

$\frac{d h / h}{d w / w}=\frac{1-h}{h}\left(\frac{1-\eta}{\eta} \theta-1\right)^{-1}$
} 


\section{Equation 53}

$$
y_{t}(j)=e^{\varepsilon_{t}^{A}} h_{t}(j)^{1-\alpha}
$$

Where $\varepsilon_{t}^{A} \sim \mathcal{N}\left(0, \sigma_{A, t}^{2}\right)$ is an IID exogenous disturbance associated with a productivity shock. The resources constraint is given by the demand from households and authorities and it is equal to: $y_{t}=c_{t}+g^{y} \bar{y} e^{\varepsilon_{t}^{G}}$.Where $\varepsilon_{t}^{G}$ is a IDD normal shock, $\bar{y}$ is the steady-state level of GDP, and $g^{y}$ is the spending to GDP ratio. Basic parameters for RBC model are: $\alpha=0.36$ (capital factor); $\beta=0,99, g^{y}=0,2 ; \sigma^{c}=2.5 ; \sigma^{L}=0.5$.

Figure 2 Basic RBC DSGE mode with productivity shock $\operatorname{VC}(1,1)=0.01^{2}$;
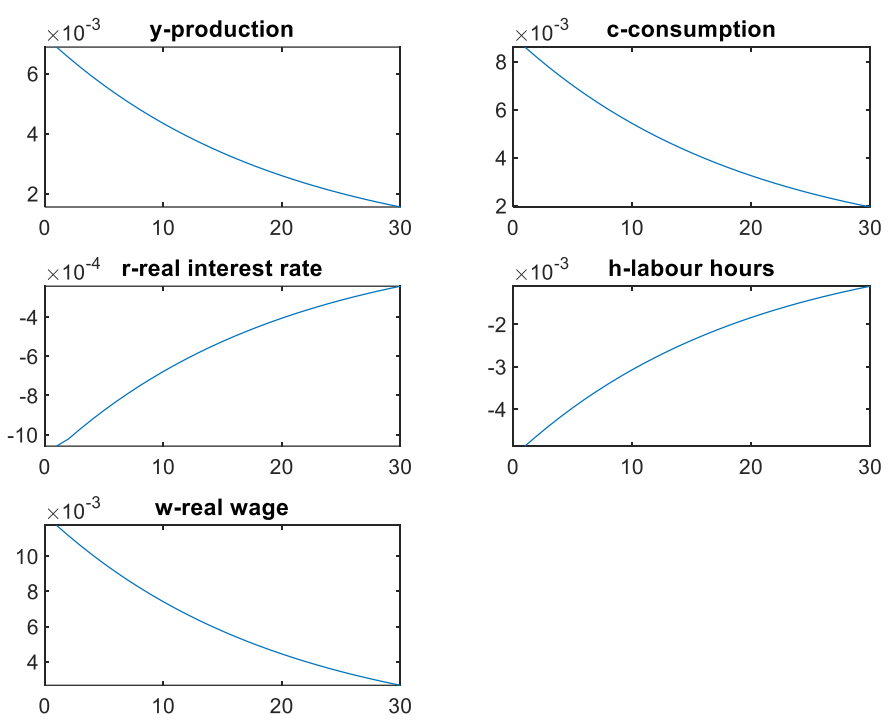

Figure 3 Basic RBC DSGE mode with spending shock $\operatorname{VC}(2,2)=0.01^{2}$;
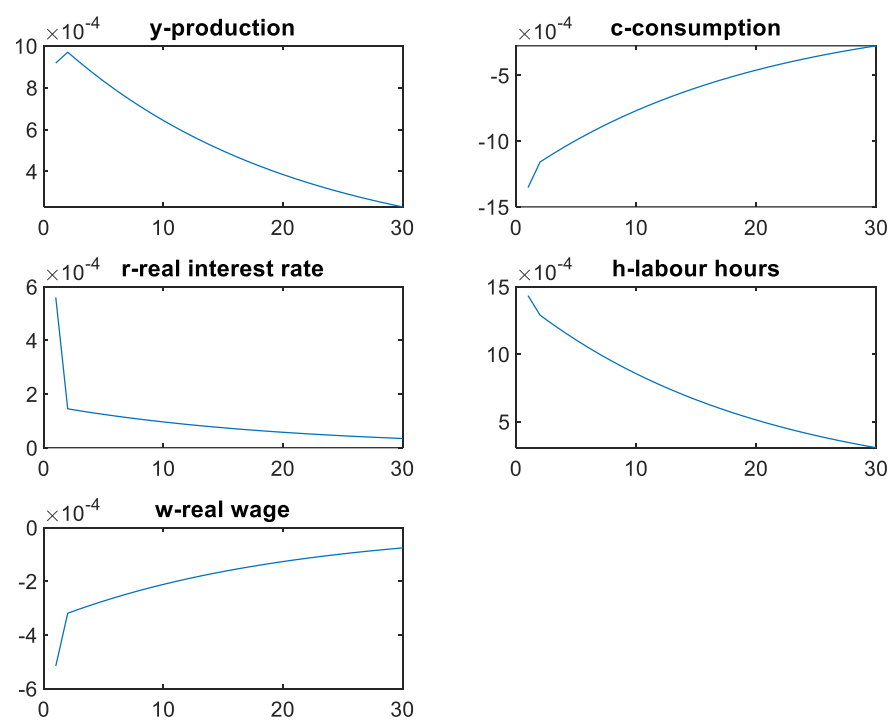

Variance covariance matrix for shocks, for productivity shock $\operatorname{VC}(1,1)=0.01^{2}$ and for spending shock $V C(2,1)=0.01^{2}$.So in the fig. 2 as production falls, real interest rate rises, same with labor hours or labor supply. Since the productivity shock many workers are 
unemployed. Also, real wage decreases with consumption decreasing also. Real interest rate here may be causing productivity fall, and downward real wage. However, with government spending shock(endogenous), productivity increases, also real wage is rising. While the real interest rate is failing. Now, the New-Keynesian model assumes that monopolistic competitive firms are price makers on the good market, but they cannot adjust prices as prices are sticky. For the price setting of this firms, see Calvo (1983). There is a continuum of monopolistic firms $i \in[0,1]$, that are choosing price $P p_{t}^{*}(i)$. Among this firms a fraction $\theta^{p}$ is not a price setter, then the price remains the same $p_{t}^{*}(i)=p_{t-1}^{*}(j)$.For the share of the firms $1-\theta^{p}$ allowed to reset their price, each firms maximizes expected sum of profits:

Equation 54

$$
\max _{p_{t}^{*}(j)} \sum_{\tau=0}^{+\infty}\left(\beta a \theta^{p}\right)^{\tau}\left(p_{t}^{*}(j)-M C_{t+\tau}(j)\right) y_{t+\tau}(j)
$$

The FOC from the previous problem, combined with the aggregate price equation and taken in logs gives rise to the New Keynesian Phillips Curve :

\section{Equation 55}

$$
\hat{\pi}_{t}=\beta E_{t} \hat{\pi}_{t+1}+\frac{\left(1-\theta^{p}\right)\left(1-\beta \theta^{p}\right)}{\theta^{p}}\left(\widehat{m c}_{t}-\hat{p}_{t}\right)
$$

Where $\widehat{m c}_{t}-\hat{p}_{t}$ are the marginal costs of the firms adjusted for inflation or additional real resources firms must spend to produce extra unit of output. Also, monetary authority controls the nominal interest rates and is concerned by both price and GDP growth. The monetary policy rule à la Taylor in logs it is:

$$
\widehat{r}_{t}=\rho^{R} \hat{r}_{t+1}+\left(1-\rho^{R}\right)\left(\phi_{r} \hat{\pi}_{t}+\phi_{y}\left(\hat{y}_{t}-\hat{y}_{t-1}\right)\right.
$$

Parameters in the NK DSGE model are : $\alpha=0.23$ which is the share of capital in output, $\beta=$ 0.99 which is a discount factor, $\delta=0.025$ representing depreciation of capital, $\sigma^{c}=1$ is a risk aversion consumption, $\sigma^{L}=2$ is a labor disutility, $g^{y}=0.2$ is a public spending to GDP.New Keynesian parameter are :

- $\theta^{p}=0.75$-it's a New-Keynesian Philips curve forward term;

- $\epsilon^{p}=10$-it's a mark-up on prices substitutability;

- $\rho^{R}=0.7$-monetary policy smoothing parameter;

- $\phi_{y}=0.025$-monetary policy GDP growth target;

- $\phi_{r}=1.5$-monetary policy inflation growth target;

Next is estimated NK DSGE model with three different shocks: First figure depicts productivity shock, next second figure depicts NK DSGE model with spending shock, in the third model there is New Keynesian model with interest rate shock. These figures are depicting the movement of real variables such as: output, consumption, investment, real wage and labor hours, also policy variables such as: real interest rate and inflation rate. 
Figure 4 New -Keynesian DSGE model with productivity shock $\operatorname{VC}(1,1)=0.01^{2}$
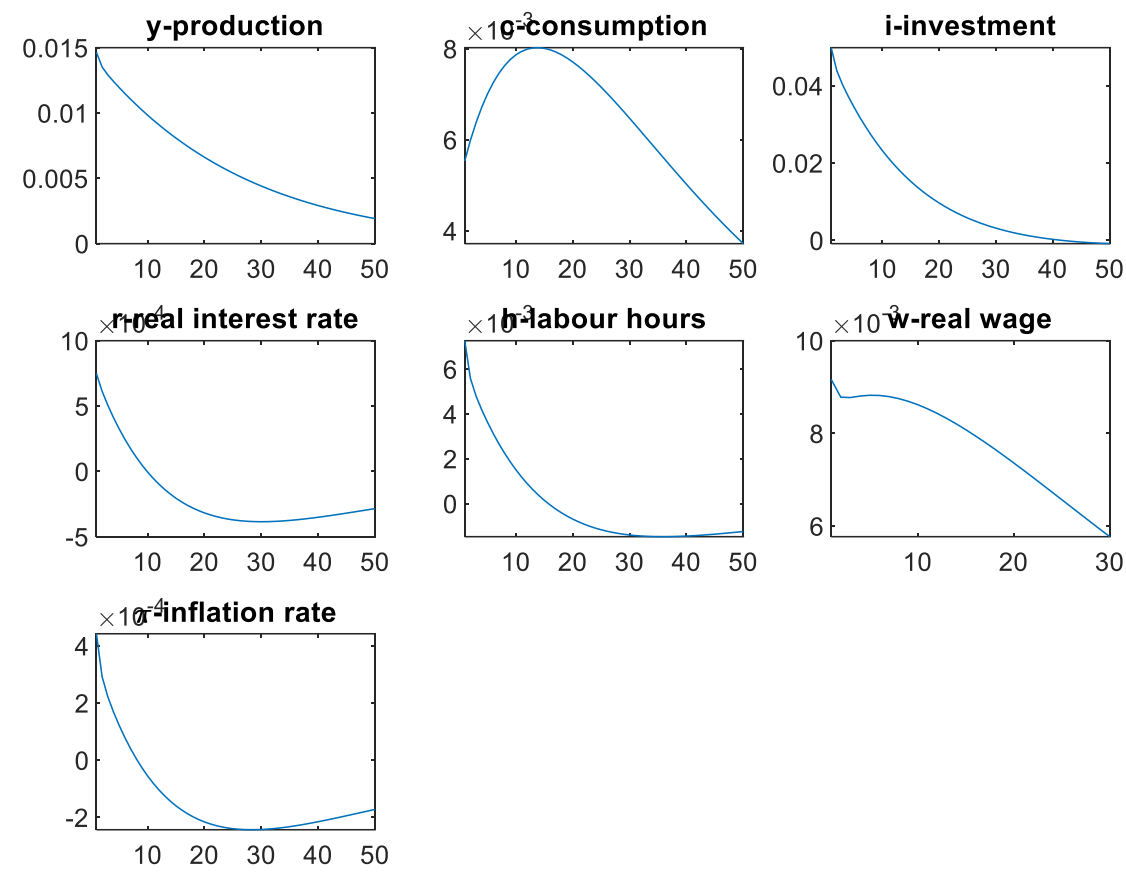

Figure 5 New -Keynesian DSGE model with spending shock $\operatorname{VC}(2,2)=0.01^{2}$;
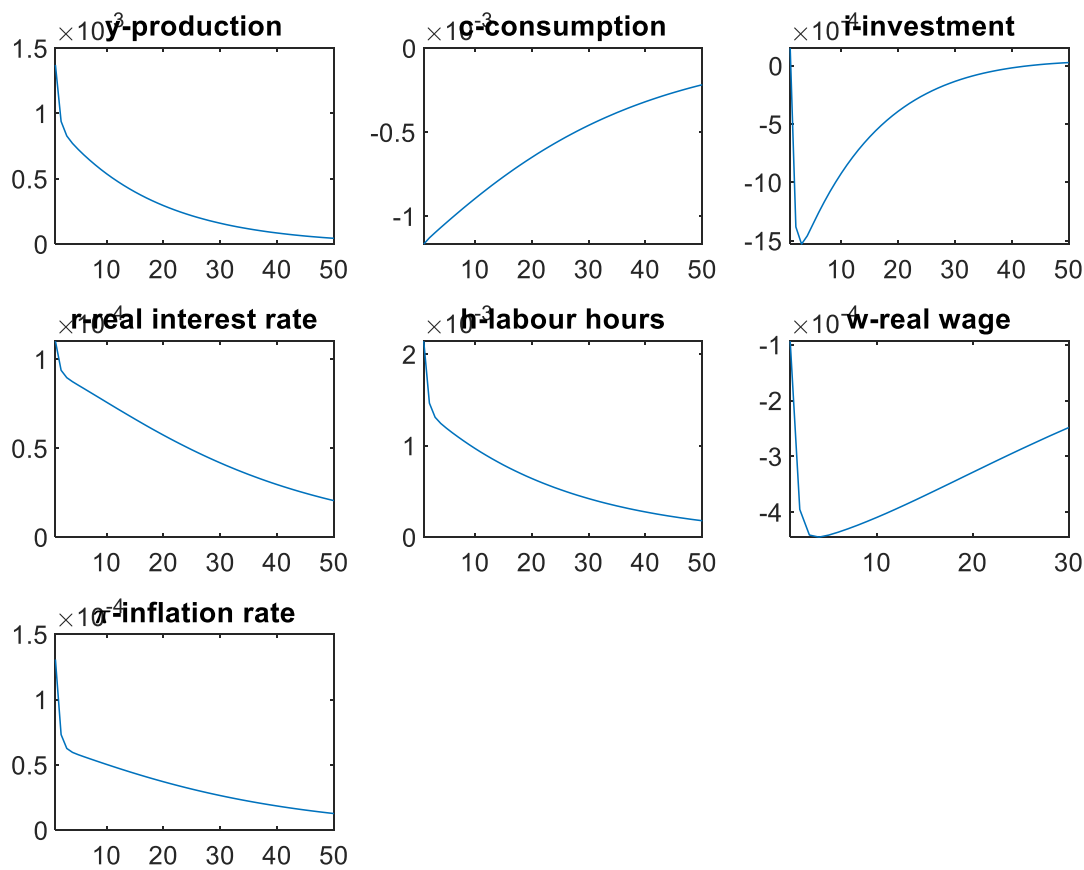
Figure 6 New -Keynesian DSGE model with interest rate shock $V C(3,3)=0.01^{\wedge} 2$;
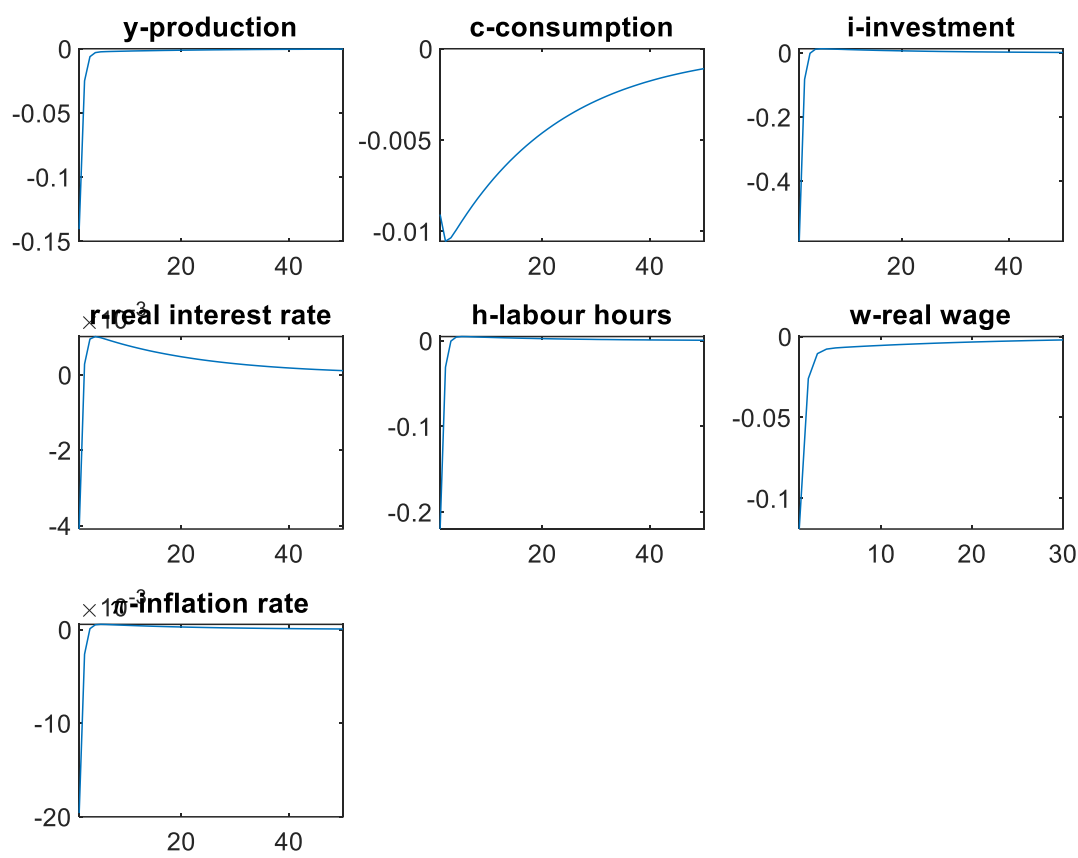

As it can be seen from the three NK models above standard reply to: productivity shock, and spending shock is the fall of interest rate induced by the monetary policy. The effects of the interest rate shock on the other side it can be seen that have not much effect on real variables except for consumption. Supply of labor as measured by the labor hours it can be see that is decreasing in case of the productivity shock, and government spending shock. Whilst in the case of interest rate shock it is relatively stable with upwards linear trend.

\section{Conclusion}

Previous presented models in this paper theoretical and empirical, have tried their best to explain what Diamond (2011) wrote in defense of his qualifications that were questioned by the Republican politicians for him taking a post as Federal reserve's chair ,...'that analysis of the labor market is in fact central to monetary policy". Theoretical models such as by Akerlof (1985), that explained that near rational behavior of some firms causes directly unemployment and a loss of output just confirms how labor market and monetary policy are dependent. Social norms also matter such norm as we have seen from Akerlof (1980) model was how we trade labor for capital. These norms are all possibility for multiple equilibria case of which only one equilibrium is neo-classical, but others are possible too. Fairness seems to play its role in price stickiness, and expectations play crucial role in determining economic activity from which level of employment or unemployment depends. Thus, in our view this macroeconomics that is concerned with monetary policy effectiveness, unemployment, notion of fairness, is basically what modern macroeconomics is about. It is essentially New Keynesian economics.

\section{References}

1. Akerlof, G. (1980). "A Theory of Social Custom, of Which Unemployment May be One Consequence”. The Quarterly Journal of Economics, 94(4), pp.749-775.

2. Akerlof, G. (1982)." Labor Contracts as Partial Gift Exchange". The Quarterly Journal of Economics, 97(4), pp.543-569. 
3. Akerlof, G. (2002). "Behavioral macroeconomics and macroeconomic behavior". The American Economic Review, 92(3), pp.411-433.

4. Akerlof, G. A. K. Rose, J. L. Yellen.(1988). "Job switching and job satisfaction in the U.S. labor market". Brookings Papers on Economic Activity 2: pp.495-594.

5. Akerlof, G.(2019)," What They Were Thinking Then:The Consequences for Macroeconomics during the Past 60 Years", Journal of economic perspectives, vol. 33, no. 4 ,

6. Akerlof, G., \& Yellen, J. (1987). "Rational Models of Irrational Behavior". The American Economic Review, 77(2), pp.137-142.

7. Alchian, A. A. (1969)." Information costs, pricing and resource unemployment". Western Economic Journal 7: 109-28.

8. Barron, J. M. (1975). "Search in the labor market and the duration of unemployment: Some empirical evidence". American Economic Review 65: 934-42.

9. Blanchard, O. J., Diamond, P. A. (1994). "Ranking, unemployment duration and wages". Review of Economic Studies 61: 417-34.

10. Blanchard, O. J., Kiyotaki, N. (1987). "Monopolistic competition and effects of aggregate demand". American Economic Review,77:647-66.

11. Blanchard, O. J., P. A. Diamond. (1989). "The Beveridge Curve". Brookings Papers on Economic Activity 1:pp. 1-60

12. Blanchard, O., Summers, L. (1986). "Hysteresis and the European Unemployment Problem". NBER Macroeconomics Annual, 1, pp.15-78.

13. Blanchard, Olivier J. (1990). "Why Does Money Affect Output? A Survey." In Handbook of Monetary Economics, edited by Benjamin M. Friedman and Frank H. Hahn, vol. 2, chap. 15. Amsterdam: Elsevier.

14. Burdett, K. (1978). "A theory of employee job search and quit rates". American Economic Review 68: 212-20

15. Calvo, G. A. (1983). "Staggered Prices in a Utility-Maximizing Framework". Journal of Monetary Economics 12 (3): pp.383-398.

16. Calvo, G. A. (1983). "Staggered prices in a utility-maximizing framework". Journal of monetary Economics, 12(3), 383-398.

17. Card, D., Chetty,R., Weber,A., (2007). "Cash-On-Hand and Competing Models of Intertemporal Behavior: New Evidence from the Labor Market" Quarterly Journal of Economics 122, pp. 1511-1560.

18. Carlsson, Mikael, Oskar Nordstrom Skans. (2012). "Evaluating Microfoundations for Aggregate Price Rigidities: Evidence from Matched Firm-Level Data on Product Prices and Unit Labor Cost." American Economic Review 102 (4): 1571-1595

19. Caselli, Mauro, Chatterjee, Arpita ;Woodland, Alan. (2017). "Multi-product Exporters, Variable Markups and Exchange Rate Fluctuations." Canadian Journal of Economics 50 (4): 1130-1160

20. Celso J. Costa (2016)." Understanding DSGE Models: Theory and Applications" ,Vernon Series in Economic Methodology.

21. Christiano, L. J., Eichenbaum, M.,Evans, C. L. (2005)." Nominal rigidities and the dynamic effects of a shock to monetary policy". Journal of political Economy, 113(1), $1-45$.

22. Contini, B., and R. Revellli. (1997). "Gross flows vs. net flows in the labor market: What is there to be learned?". Labour Economics 4: 245-63.

23. De Loecker, Jan, Pinelopi K. Goldberg, Amit K. Khandelwal, Nina Pavcnik.( 2016). "Prices, Markups and Trade Reform." Econometrica 84 (2): 445-510. 
24. Diamond, P. A. (1981). "Mobility costs, frictional unemployment, and efficiency". Journal of Political Economy 89: 789-812.

25. Diamond, P. A., Maskin, E. (1979). “An equilibrium analysis of search and breach of contract”. Bell Journal of Economics 10: pp.282-316.

26. Diamond, Peter A.(1982). "Aggregate Demand Management in Search Equilibrium," Journal of Political Economy 90(5), 881-894

27. Diamond, Peter A.(2011). "When a Nobel Prize Isn't Enough", The New York Times

28. Eyster,E.,Madarsz,K.,Michaillat,P.( 2019). "Pricing under Fairness Concerns,",preprint arXiv:1904.05656v3 [econ.TH]

29. Fehr, Ernst, and Klaus M. Schmidt. (1999). "A Theory of Fairness, Competition, and Cooperation." Quarterly Journal of Economics 114 (3): pp.817-868.

30. Friedman, M. (1968). "The role of monetary policy". American Economic Review 58: $1-17$.

31. Ganapati, Sharat, Joseph S. Shapiro, and Reed Walker. (2019). "Energy Cost PassThrough in US Manufacturing: Estimates and Implications for Carbon Taxes." American Economic Journal: Applied Economics

32. Hall, R. E. (1979). "A theory of the natural unemployment rate and the duration of employment". Journal of Monetary Economics 5: pp.153-69.

33. Jovanovic, B. (1979). "Job matching and the theory of turnover". Journal of Political Economy87: 972-90.

34. Kahneman, Daniel, Jack L. Knetsch, and Richard Thaler. (1986). "Fairness as a Constraint on Profit Seeking: Entitlements in the Market." American Economic Review 76 (4): 728-41.

35. Keynes, J.M. (1936).” The General Theory of Employment, Interest and Money”.New York

36. Lucas, R. E., Prescott, E. C. (1974). "Equilibrium search and unemployment”. Journal of Economic Theory 7: 188-209.

37. Mankiw, N. Gregory, and Ricardo Reis. (2010). "Imperfect Information and Aggregate Supply." In Handbook of Monetary Economics, , vol. 3A, chap. 5. Amsterdam: Elsevier.

38. McKenna, C. J. (1987)." Labour market participation in matching equilibrium". Economica 57: 325-33.

39. Mortensen, D. T. (1970a). "A theory of wage and employment dynamics". In The Microeconomic Foundations of Employment and Inflation Theory, eds. E. S. Phelps et al. New York: Norton.

40. Mortensen, D. T.(1970b) A. "Job Search, the Duration of Unemployment and the Phillips Curve." A.E.R. 60 (December1970): 847-62.

41. Mortensen, D. T., and C. A. Pissarides. (1994). "Job creation and job destruction in the theory of unemployment". Review of Economic Studies 61: 397-415. New York 1936.

42. Phelps, E. S. (1967). "Phillips curves, expectations of inflation and optimal unemployment". Economica 34: 254-81.

43. Phelps, E. S. (1968). "Money-wage dynamics and labor-market equilibrium". Journal of Political Economy 76: 678-711

44. Phelps, E. S., et al. (1970). "Microeconomic Foundations of Employment and Inflation Theory". New York: Norton.

45. Pissarides ,C.(2000),'Equilibrium Unemployment Theory”. Cambridge MA:MIT Press, 1990 (Second edition 2000)

46. Pissarides, C. (1979)." Job matchings with state employment agencies and random search". Economic Journal 89: 818-33. 
47. Pissarides, C. A. (1984). "Search intensity, job advertising and efficiency". Journal of Labor Economics 2: 128-43.

48. Rabin, M. (1993). "Incorporating Fairness into Game Theory and Economics." American Economic Review 83 (5): 1281-1302

49. Rotemberg, J. J. (1982). "Sticky prices in the United States". Journal of Political Economy, 90:pp.1187-211.

50. Rotemberg, J., Woodford, M. (1997). "An optimization-based econometric framework for the evaluation of monetary policy. In NBER Macroeconomics Annual 1997, Volume 12 (pp. 297-361).MIT Press.

51. Rotemberg, Julio J. (2005). "Customer Anger at Price Increases, Changes in the Frequency of Price Adjustment and Monetary Policy." Journal of Monetary Economics 52 (4): 829-852.

52. Rotemberg, Julio J. (2011). "Fair Pricing." Journal of the European Economic Association 9 (5): 952-981

53. Rothschild, M. (1973). "Models of market organization with imperfect information: A survey". Journal of Political Economy 81: 1283-1308.

54. Smets, F., \& Wouters, R. (2003). "An estimated dynamic stochastic general equilibrium model of the euro area". Journal of the European economic association, 1(5), 1123 1175 .

55. Smets, F., \& Wouters, R. (2007). "Shocks and frictions in US business cycles: A Bayesian DSGE approach". National bank of belgium working paper, (109).

56. Solow, R.,(1979), "Another Possible Source of Wage Stickness", Journal of Macroeconomics 1,pp.79-82.

57. Taylor,J.B. (1979), "Staggered wage setting in a macro model". American Economic Review, Papers and Proceedings 69 (2), pp. 108-13

58. Tobin, J. (1972). "Inflation and unemployment". American Economic Review 62: pp.118 